\title{
Visualising public transport accessibility to inform urban planning policy in Hubli-Dharwad, India
}

\author{
Bhargav Adhvaryu (D) Sushmita S. Mudhol
}

Accepted: 5 November 2021 / Published online: 23 November 2021

(C) The Author(s), under exclusive licence to Springer Nature B.V. 2021

\begin{abstract}
Rapid urbanisation in India is a key contributor to the overstressed public infrastructure. The urban public transport system is one of the important infrastructure systems. An effective public transportation network helps the city improve its accessibility, lower carbon footprint, and enhances economic growth and societal equity. India is a relatively poor country with limited public resources. Therefore, investing in an effective urban public transport system needs a tailored approach. Such an approach would entail using public transport to guide urban development. In this context, the first step would be to measure the accessibility levels of the existing public transport network and then use the accessibility mapping outputs to better inform the urban planning process. This study explores the Public Transport Accessibility Level (PTAL) tool that measures the accessibility of the public transport system and provides a spatial visualisation using Geographic Information System. PTAL is implemented taking Hubli-Dharwad as a case study for the base year
\end{abstract}

B. Adhvaryu ( $\square)$

Amrut Mody School of Management, Ahmedabad

University, Commerce Six Roads,

Navrangpura, Ahmedabad 38009, India

e-mail: bhargav@cantab.net

S. S. Mudhol

Directorate of Urban Land Transport, Government of

Karnataka, Bengaluru, India

e-mail:sushmitamudhol@gmail.com
(2020) superimposed with population and employment density, and future year (2031). The outcome of the research facilitates the city planning process by guiding transportation and land-use zoning integrations, direct public transport investments, demarcation of transit-oriented development zones, parking policies, and identifying locations of affordable and lowcost housing.

Keywords Public transport accessibility - Urban planning policy $\cdot$ Spatial analysis $\cdot$ Developing countries $\cdot$ Land use - transport integration

\section{Introduction}

Accessibility in the context of human settlements is generally perceived as the ease of access to goods and services across various destinations. In that sense, a transport system becomes more significant when its ability to provide access increases. A transport system in a city can be perceived to have two key components: a network of right-of-ways for circulation of vehicles both public and private and the supporting infrastructure (roads, traffic signals, railway lines, public transport stops, terminals, depots, etc.). Adding more and more roads has been argued as not being the solution to improve accessibility as it is associated with environmental issues and delivers only short- 
term benefits due to the induced travel phenomenon (Litman, 2012; Noland, 2001). On the other hand, investing in the public transport (PT) system is considered more effective as it has lesser environmental issues and addresses the broader social equity in transport especially for the urban poor who have no other mobility choice except public transport.

Several studies have highlighted the benefits of improving public transport. The transport network primarily caters to providing the people access to businesses, education, recreation, and social interaction to exchange goods and services (Miller, 2018). Therefore, improving the public transport accessibility in service coverage and availability can evolve the transport system and can help cater to a larger population (Saghapour et al., 2016). The public transport systems of a city range from city buses, bus rapid transit system (BRTS), sub-urban railways, monorail, to metrorail. Buses make up more than $90 \%$ of the urban public transport system in Indian cities (Pucher \& Korattyswaroopam, 2004). The rising population has increased the demand for public transport services, most of which are overcrowded. Hence, it is necessary to measure and analyse the service accessibility levels of the existing public transport system. PTAL is one such tool that measures the service accessibility levels of the public transport system and provides a spatial visualisation. This visualisation can help in spatial planning, streamlining land use zoning, and guiding future public transport investments that are in synchronisation with urban development.

Buses are one of the most financially and economically sustainable modes to serve a society since they can provide higher-order mobility to a greater community with minimal costs (Adwani \& Tiwari, 2006) and can be invested in incrementally as the demand rises. Therefore, in this study, intercity buses operated by the government are used to assess the public transport accessibility levels.

Karnataka has the third-highest bus mode share for work with excellent dependency for inter and intrastate transport (Census India, 2011) in the country. In Karnataka, Hubli-Dharwad has the fifth-highest bus ridership for work. The city has a $50 \%$ bus mode share compared to various Indian cities (Adwani \& Tiwari, 2006). This shows the magnitude of reliance on public transport considering the size and scale of the city.
The twin cities of Hubli-Dharwad are one of the fastest-growing cities in Karnataka with an area of 402 $\mathrm{km}^{2}$ and a population of 0.93 million. The cities are the linchpin of business and educational hubs, respectively, for North Karnataka (HDUDA, 2018). Many people commute between the two cities for work, education, shopping, etc., most trips are made by public transport (22\% PT, 23\% walking, 19\% cycling, $36 \%$ private modes). In 2018, hinging on the high city bus ridership, BRTS was introduced in Hubli-Dharwad. The ridership of the BRTS increased from 15,000 passengers/day to 99,000 passengers/day in ayear. It has since bagged the Union Government's "Best Urban Mass Transit Project" for 2019 (HubballiDharwad BRTS Company Ltd., 2020). It is the second-highest ridership after Ahmedabad (EMBARQ, 2020).

The city follows a Master Plan 2031 Revision-II (made in 2017 and approved in 2019), which has opened new areas for development. This establishes the need to also analyse the accessibility of the public transport network in relation to the planned future developments in addition to the analysis of the current situation.

Accessibility of public transport systems is a vital indicator of the network's strength and functionality. The mapping provides a visual representation of the existing accessibility levels that would enhance the master plan decisions and guide future public transport investments, rationalise land use distribution, help decide sites for affordable housing locations, support transit-oriented development (TOD) zone demarcation, and parking policy. In the recent past, the concept of TOD has been at the forefront. TODs are compact, mixed-use developments that facilitate walking, cycling, and use of public transport through their urban planning and design interventions. The measure of TOD performance is mainly focused on increasing patronage and active travel while reducing car use. Often a framework applied for characterising TODs has been drawn on the Node-Place (N-P) model proposed by Bertolini (1999) and has since been enhanced through various augmentations. The model predominantly suggests that transport and land use are shaping the development of the station precincts, with land use creating the need for mobility and transport. Conversely, the availability of transport services makes certain locations more accessible and affects location (Olaru et al., 2019). Hence, accessibility is a 
prominent factor to analyse the service level of the network to further facilitate TOD.

The data collection which included walk speed surveys, bus route and frequency for city bus and BRTS, and interviews with officials were taken up in December 2019 and were completed by February 2020. The base year for PTAL analysis is therefore selected to be 2020 since the data collected was from January 2020. The future year for mapping PTAL year was considered to be 2031 as it aligns with the Master Plan 2031. A future scenario is created to facilitate base and future comparisons. (2031) mapping were therefore selected to create an analysis that helps visualise the current year PT network and generate future scenarios with proposals conducive to the Master Plan 2031.

\section{Methods to measure public transport accessibility}

Measuring the level of accessibility provided by public transport and its subsequent mapping has several important facets. First, a baseline scenario where PT is lacking can inform the current improvement needs when superimposed with a population distribution map. Second, a future PT accessibility scenario when overlaid on the master plan's future land development scenarios, can inform the planning process and future transport investments, providing an opportunity to achieve better synchronisation between the two. Either can be adjusted to find optimum balance, making the approach more integrated. There are several methods to measure PT accessibility levels. Some such methods namely Land Use \& Public Transport Accessibility Index (LUPTAI), Time-Based Transit Service Area Tool (TTSAT), Transit Opportunity Index (TOI), and Public Transport Access Level (PTAL), are briefly explained below.

Time-Based Transit Service Area Tool (TTSAT) is a time-based method to assess accessibility with a visual representation of transit service coverage. This methodology incorporates total trip travel time into the transit area maps. Accessibility of a point of interest (POI) is measured for the number of destinations that can be accessed within a given maximum travel-time cost including transit access, egress, and in transit time (Cheng \& Agarwal, 2010). The level of accessibility is analysed for a pre-existing transit system. Also, the users can set many of the input variables according to their preferences like maximum budget, travel time, and wait time. Data required are stop locations, route frequency, road network, location of all probable destinations, maximum preferable walk distance and time, and in-transit travel time. The process requires intense computations as accessibility is to be calculated for each combination of origin and destination within a given maximum travel time with access, egress, and in transit travel time.

The Land Use \& Public Transport Accessibility Index (LUPTAI) measures how easy it is to access common destinations (e.g. health, education, retail, banking, and employment) by walking and/or public transport (Pitot et al., 2010). It measures accessibility as the ease of access to destinations from various origins by walking and PT within a given maximum travel time/cost. This method was the first of its kind to consider public transport as the means of access rather than a mere facility to be accessed. The study uses a five-colour scale that shows the levels of access for any given area, highlighting areas of no, poor, low, medium, or high accessibility.

TTSAT requires intense computations as accessibility is to be calculated for each combination of origin and destination within given maximum travel time with access, egress, and in transit travel time. LUPTAI is a destination-based approach, i.e., calculations are from destination to origin. The procedure is similar to TTSAT and requires the same data but is comparatively less demanding. Both TTSAT and LUPTAI are relatively more data and calculation-intensive as compared to PTAL.

The Transit Opportunity Index (TOI) is a new method of public transit quality of service measure, which considers both transit accessibility and transit connectivity. The TOI provides a standard framework for evaluating public transit service based on spatial and temporal coverage measures which mainly pertains to transit accessibility and trip coverage measures that consider origin-destination connectivity. Very few consider trip coverage i.e. whether a public transit service is available for specific trip origin/ destinations. The computations incorporate transit accessibility for each O-D pair in a transit network by calculating spatial coverage for each origin or destination and service frequency for each O-D pair which includes temporal coverage. Trip connectivity between origin and destination is calculated with trip coverage aggregated overall transit lines based on the 

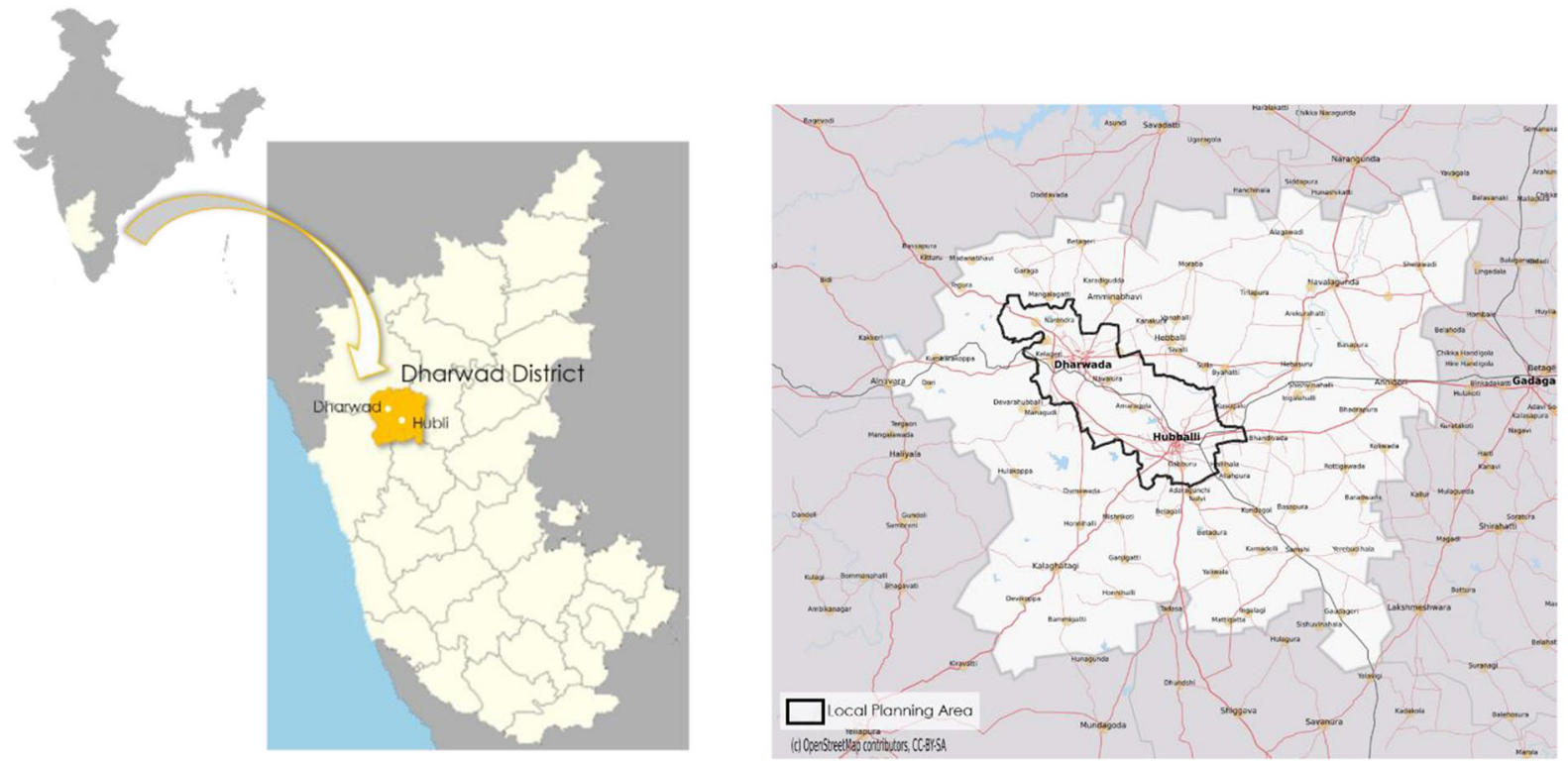

Fig. 1 Location of Hubli-Dharwad. Source: Wikimedia Commons, (2020), Source: Wikimedia Commons, (2011)

Table 1 Population of Indian cities with its percentage of bus trips

\begin{tabular}{llc}
\hline City & $\begin{array}{l}\text { Percentage of trips } \\
\text { by bus }\end{array}$ & $\begin{array}{l}\text { Population (millions) } \\
2001\end{array}$ \\
\hline Nagpur & 5 & 2.05 \\
Vadodara & 15 & 1.30 \\
Kanpur & 18 & 2.53 \\
Ahmedabad & 27 & 3.45 \\
Tripura & 28 & 0.60 \\
Pune & 29 & 2.54 \\
Mumbai & 29 & 8.60 \\
Bhopal & 30 & 1.43 \\
Vijayawada & 34 & 1.01 \\
Bangalore & 42 & 6.50 \\
Guwahati & 47 & 0.80 \\
Visakhapatnam & 47 & 1.32 \\
Madras & 49 & 6.40 \\
Hubli- & 50 & 0.60 \\
Dharwad & & 1.66 \\
Cochin & 54 & 13.78 \\
Delhi & 62 & 0.62 \\
Shimla & 86 & 14.00 \\
Calcutta & 89 & \\
\hline Source & &
\end{tabular}

Source: Adwani \& Tiwari, (2006) existence of a direct route from an origin to a destination on a particular transit line. The Transit Opportunity Index (TOI) for each O-D pair is calculated using transit accessibility and the connectivity parameter with decay to reflect decreasing connectivity with increased travel time. This tool facilitates analysis of the public transit opportunity between a single O-D pair and also overall public transit opportunity from or to a specific origin or destination. (Mamun et al., 2013). Therefore, the O-D data set is one of the prominent requirements for this tool which is difficult to obtain for Indian cities due to data constraints.

Public transport accessibility assessments are a highly detailed measure of the accessibility of any point of origin to the PT network dependent on walk access time and service availability. It primarily enables comparisons between the relative accessibility existing at different locations within the city and the relative effects on such accessibility of introducing different schedules or levels of service (Wu \& Hine, 2003).

Public Transport Access Level (PTAL) is a way of measuring access to the public transport network which was developed by the London Borough of Hammersmith \& Fulham (Transport for London (TfL), 2015). The dataset requires four important components, namely, points of interest (POI), service 


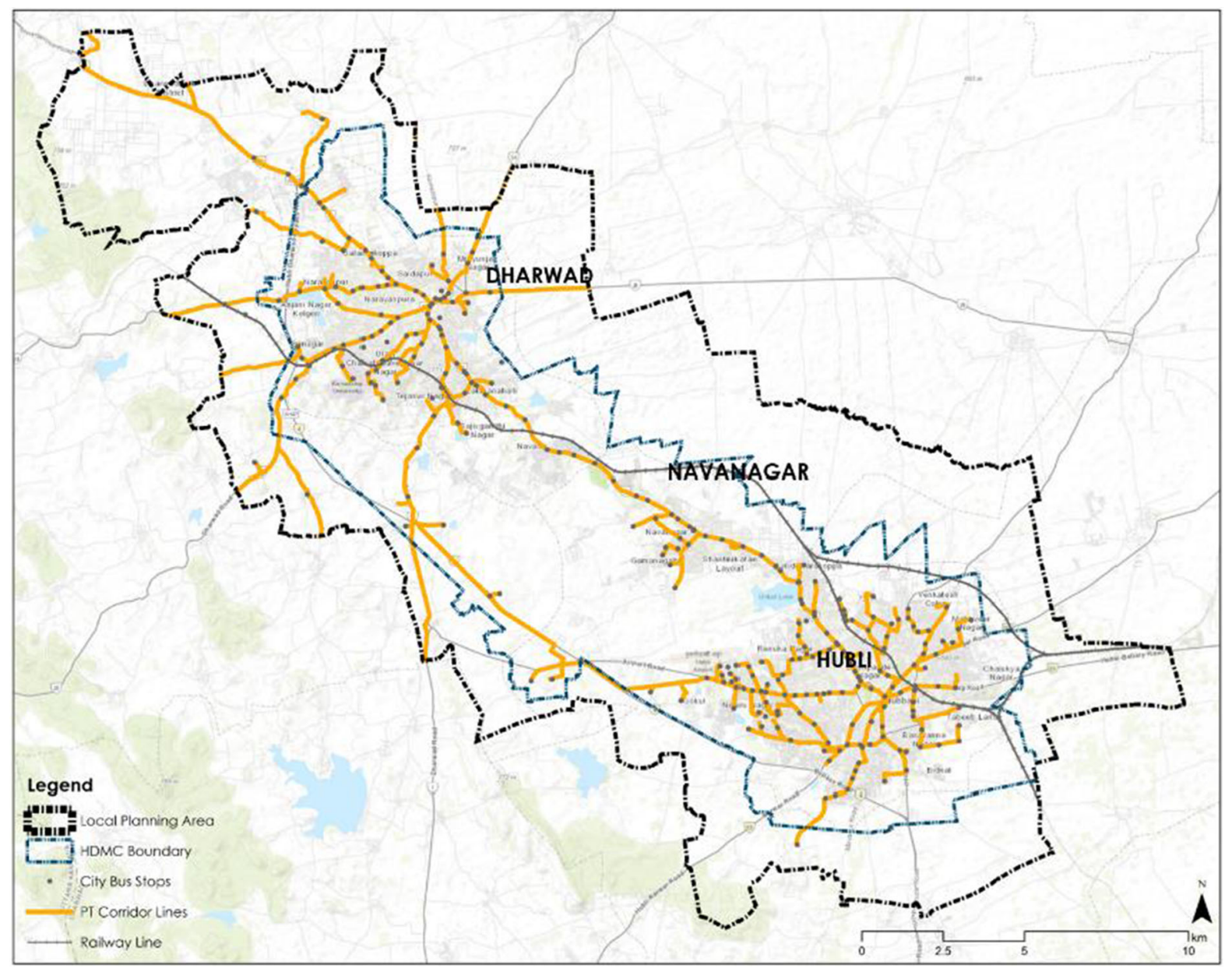

Fig. 2 City bus) routes

access points (SAP), walk network, and service frequency data. The data analysed is a combination of walk access time to avail public transport with service availability at network points like stations, bus stops, etc. within a catchment area. A public transport accessibility index (PTAI) is calculated from this data and converted to PTAL with levels ranging from 0 to $6 \mathrm{~b}$, where PTAL 0 is the lowest and PTAL $6 \mathrm{~b}$ the highest level of connectivity. These values are often represented in a pre-set set of colours. The key strengths of the methodology are the output which is relatively easy to interpret, helps compare different areas inconsistent manner, simplicity in calculation method, a wide range of applications at macro and micro level, acts as a proxy for access to services and jobs in the areas (Cooper \& Inayathusein, 2018). The limitations of PTAL are that it only considers access to the PT network and not the distance one can travel through the network. Due to the categorisation of PTAL values into just nine categories, places with the same PTAL value can have a significantly different characteristic in terms of connectivity which do not show up on the mapping. The method does not consider the impact of vehicle capacity, reliability, or possible interventions to improve station capacity. The method also overlooks the possible frequency of service of peak hours during other times of the day or weekends and focuses on only morning peak during weekdays (Cooper \& Inayathusein, 2018).

TfL further produced a new methodology called travel time mapping to obtain a richer picture taking into consideration the limitations of PTAL. The maps use a set of colours to show the time taken to travel between one selected location to all other locations. 


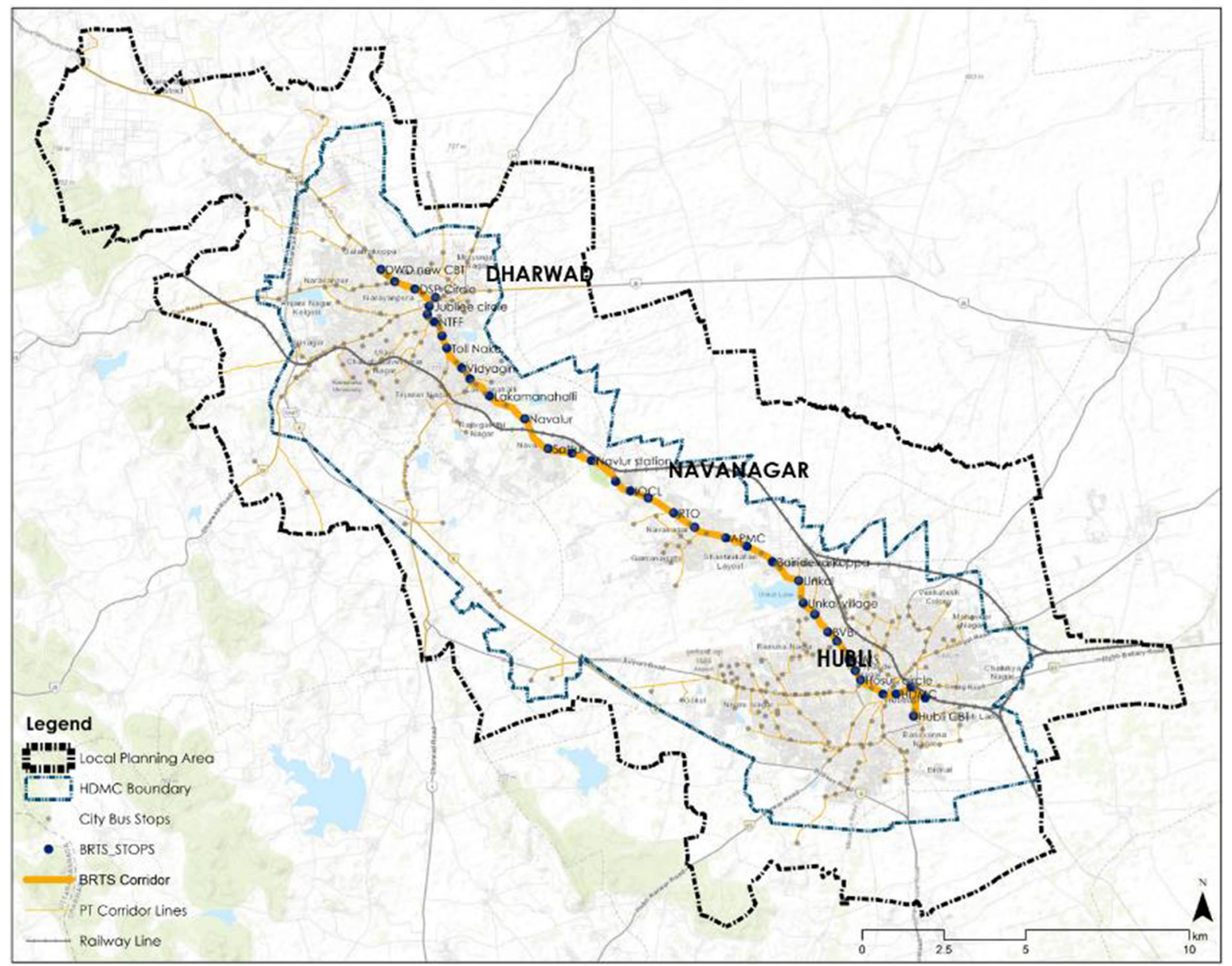

Fig. 3 Bus rapid transit system (BRTS)

This methodology uses the Railplan model, which splits the area of London into several zones representing all the places that people travel to and from, estimate their likely routes, and estimate the travel time. Two different approaches for creating travel time maps, namely Time Mapping (TIM) and Calculator of Public Transport Access in London (CAPITAL). TIM contains only travel time between the zones, with origins and destinations (O\&D) as the centres of the modelled zones. Hence, each zone in the model gets one colour. Beneficial for the study to focus on an area and not on a specific site. CAPITAL, on the other hand, covers travel time from zone to zone in the zone-based model and the time it takes to access the transport network within the O\&D zone (Transport for London, 2015). This method, unlike TIM where origins and destinations are always the centers of the modelled zones, accepts user-defined origins and destinations that the travel times are calculated for.

The PTAI in Melbourne area in Australia focused on measuring access to PT stops while considering population levels in conjunction with walk time and service frequency. It includes two main parts, the PTAI and the assessment and comparison of the index using the Victorian Integrated Survey of Travel and Activity dataset (VISTA) data (Saghapour et al., 2016). It is designed to be applied with available census and transport modelling tools. The study does not consider the connectivity between public modes that may influence accessibility, mainly in areas of low accessibility. 
Table 2 Key PTAL adaptations: London, Ahmedabad, Surat, and Hubli-Dharwad

\begin{tabular}{|c|c|c|c|c|c|}
\hline Parameter & London & Ahmedabad & Surat & $\begin{array}{l}\text { Hubli- } \\
\text { Dharwad }\end{array}$ & $\begin{array}{l}\text { Adaptation rationale for Hubli-Dharwad } \\
\text { (where applicable) }\end{array}$ \\
\hline Peak Hour & $\begin{array}{l}8: 15 \mathrm{am}- \\
9: 15 \mathrm{am}\end{array}$ & 9:30am-10:30am & $\begin{array}{l}\text { 9:00am- } \\
\text { 10:00am }\end{array}$ & $\begin{array}{l}\text { 9:00am - } \\
\text { 10:00am }\end{array}$ & - \\
\hline $\begin{array}{l}\text { Walk } \\
\text { Speed }\end{array}$ & $\begin{array}{l}4.8 \mathrm{~km} / \mathrm{h} \\
(80 \mathrm{~m} / \\
\min )\end{array}$ & $3.6 \mathrm{~km} / \mathrm{h}(60 \mathrm{~m} / \mathrm{min})$ & $\begin{array}{l}3.6 \mathrm{~km} / \mathrm{h} \\
(60 \mathrm{~m} / \\
\min )\end{array}$ & $\begin{array}{l}3.6 \mathrm{~km} / \mathrm{h} \\
(60 \mathrm{~m} / \\
\min )\end{array}$ & $\begin{array}{l}\text { The existing pedestrian infrastructure is not as } \\
\text { conducive as that of London to achieve the } \\
\text { same walking speeds. Therefore, a } \\
\text { convenience-based sample survey was } \\
\text { conducted to establish the walk speed. }\end{array}$ \\
\hline $\begin{array}{l}\text { Reliability } \\
(K)\end{array}$ & $\begin{array}{l}\text { Bus- } \\
2 \text { min }\end{array}$ & $\begin{array}{l}\text { City Bus-2.5 min BRTS- } \\
1 \mathrm{~min}\end{array}$ & $\begin{array}{l}\text { City Bus- } \\
4 \text { min } \\
\text { BRTS- } \\
1 \text { min }\end{array}$ & $\begin{array}{l}\text { City Bus- } \\
2.5 \text { min } \\
\text { BRTS- } \\
1 \text { min }\end{array}$ & $\begin{array}{l}\text { The value of } 2.5 \text { min for City bus and } 1 \text { min for } \\
\text { BRTS is established using a convenience- } \\
\text { based sample survey. As compared to } \\
\text { London, the reliability of buses that move in } \\
\text { mixed traffic conditions in Indian cities are } \\
\text { assumed to be lower owing to the } \\
\text { unpredictability of traffic conditions and } \\
\text { violations }\end{array}$ \\
\hline $\begin{array}{l}\text { Max. walk } \\
\text { time }\end{array}$ & $8 \mathrm{~min}$ & $\begin{array}{l}\text { The max distance of an SAP } \\
\text { from a POI was } 993 \mathrm{~m} \\
\text { (16 min) so no threshold }\end{array}$ & $\begin{array}{l}\text { City Bus- } \\
10 \text { min } \\
\text { BRTS- } \\
15 \text { min }\end{array}$ & $\begin{array}{l}\text { City Bus- } \\
10 \text { min } \\
\text { BRTS- } \\
15 \text { min }\end{array}$ & $\begin{array}{l}\text { The value of } 10 \text { min for the City bus and } \\
15 \text { min for BRTS is established using a } \\
\text { convenience-based sample survey. Because } \\
\text { of the high dependency on PT modes due to } \\
\text { the linear structure of the city, the willingness } \\
\text { to walk was observed to be higher than that of } \\
\text { London }\end{array}$ \\
\hline $\begin{array}{l}\text { Max. walk } \\
\text { distance }\end{array}$ & $640 \mathrm{~m}$ & & $\begin{array}{l}\text { City Bus- } \\
600 \mathrm{~m} \\
\text { BRTS- } \\
900 \mathrm{~m}\end{array}$ & $\begin{array}{l}\text { City Bus- } \\
600 \mathrm{~m} \\
\text { BRTS- } \\
900 \mathrm{~m}\end{array}$ & - \\
\hline
\end{tabular}

Source: London (Transport for London, 2010); Ahmedabad (Adhvaryu \& Shah, 2016); Surat (Adhvaryu, et al., 2019)

In the Indian context, considering the resource and data constraints, (Adhvaryu \& Shah, 2016) demonstrated the first city-wide application of PTAL mapping in Ahmedabad. The study incorporated a grid approach (using $1 \mathrm{~km}^{2}$ ) as compared to the POIs considered by built development in the London method. The peak hour, walking speed, and reliability factor were adjusted to the city's context. The study discusses various uses of PTAL mapping in different urban planning practices.

Following the Ahmedabad model, PTAL was mapped for the city of Surat. The study overlaid the PTAL mapping onto population density maps to showcase improved decision-making processes on PT investments. It demonstrated the use of PTAL maps in evaluating future transport investment options by creating "what-if" scenarios (Adhvaryu et al., 2019). The paper also discusses the uses of PTAL mapping in city planning and suggests mapping on micro scales to help enhance station-level planning and TOD policies. A recent study (Adhvaryu \& Kumar, 2021) in Lucknow demonstrated the application of PTAL mapping in urban planning policy.

These three studies in the Indian context have discussed the advantages of using PTAL mapping for Indian cities where data and resource constraints are predominant issues. The studies discuss the adaptability of PTAL to available data to create clear visualisations to facilitate urban planning policy. The study, given the advantages, uses PTAL methodology. A further innovation in terms of the categorization of accessibility levels is explained in "Data collection and analysis" Section . 
Table 3 Sample calculation of accessibility index for a point of interest

\begin{tabular}{|c|c|c|c|c|c|c|c|c|c|c|c|c|}
\hline POI & Mode & SAP & $\begin{array}{l}\text { Route. } \\
\text { No }\end{array}$ & $\begin{array}{l}\text { Distance } \\
(\mathrm{m}) \text { from SAP to } \\
\text { POI }\end{array}$ & $\begin{array}{l}\text { Frequency } \\
\text { (per hour) }\end{array}$ & $\begin{array}{l}\text { Reliability } \\
\text { factor (k) }\end{array}$ & $\begin{array}{l}\text { WT } \\
\text { mins }\end{array}$ & $\begin{array}{l}\text { AWT } \\
\text { mins }\end{array}$ & $\begin{array}{l}\text { TAT } \\
\text { mins }\end{array}$ & Weight & $\begin{array}{l}\text { EDF } \\
\text { per } \\
\text { hour }\end{array}$ & AI \\
\hline \multirow[t]{10}{*}{101} & \multirow[t]{8}{*}{ BRTS } & \multirow{4}{*}{$\begin{array}{l}\text { Court } \\
\text { Circle }\end{array}$} & $201 B$ & 201 & 15 & 1 & 3.35 & 3 & 6.35 & 0.5 & 4.72 & 2.36 \\
\hline & & & $100 D$ & 201 & 16 & 1 & 3.35 & 4 & 7.35 & 1 & 4.08 & 4.08 \\
\hline & & & $200 A$ & 201 & 6 & 1 & 3.35 & 6 & 9.35 & 0.5 & 3.2 & 1.6 \\
\hline & & & $200 D$ & 201 & 6 & 1 & 3.35 & 6 & 9.35 & 0.5 & 3.2 & 1.6 \\
\hline & & \multirow[t]{4}{*}{ Jubilee } & $201 B$ & 550 & 15 & 1 & 9.16 & 3 & 12.16 & 0.5 & 2.46 & 1.23 \\
\hline & & & $100 D$ & 550 & 16 & 1 & 9.16 & 4 & 13.16 & 1 & 2.27 & 2.27 \\
\hline & & & $200 A$ & 550 & 6 & 1 & 9.16 & 6 & 15.16 & 0.5 & 1.97 & 0.98 \\
\hline & & & $200 D$ & 550 & 6 & 1 & 9.16 & 6 & 15.16 & 0.5 & 1.97 & 0.98 \\
\hline & \multirow{2}{*}{$\begin{array}{l}\text { City } \\
\text { Bus }\end{array}$} & \multirow{2}{*}{$\begin{array}{l}\text { Court } \\
\text { circle }\end{array}$} & 1 & 65.63 & 4 & 2.5 & 1.09 & 10 & 11.09 & 1 & 2.70 & 2.7 \\
\hline & & & 2 & 70 & 3 & 2.5 & 1.16 & 12.5 & 13.66 & 0.5 & 2.19 & 1.09 \\
\hline
\end{tabular}

Key $P O I=$ point of interest $; S A P=$ service access point $; W K T=$ walk time $; A W T=$ average waiting time $;$ TAT = total access time; $E D F=$ equivalent doorstep frequency; $A I=$ accessibility index

\begin{tabular}{|c|c|c|c|}
\hline PTAL & $\begin{array}{l}\text { Access Time } \\
\text { (Minutes ) }\end{array}$ & $\begin{array}{c}\text { Accessibility } \\
\text { Index (AI) }\end{array}$ & $\begin{array}{c}\text { Level of } \\
\text { Accessibility }\end{array}$ \\
\hline Level 1 & Nil & 0 & \multirow[b]{10}{*}{$\downarrow$ Excellent } \\
\hline Level 2 & $>60$ & $0-1$ & \\
\hline Level 3 & $45-60$ & $1-1.5$ & \\
\hline Level 4 & $30-45$ & $1.5-2$ & \\
\hline Level 5 & $20-30$ & $2-3$ & \\
\hline Level 6 & $15-20$ & $3-4$ & \\
\hline Level 7 & $10-15$ & $4-6$ & \\
\hline Level 8 & $5-10$ & $6-12$ & \\
\hline Level 9 & $2-5$ & $12-30$ & \\
\hline Level 10 & $<2$ & $>30$ & \\
\hline
\end{tabular}

Fig. 4 Categorisation of accessibility index values for thematic mapping. Note: Access Time and AI are in terms of equivalent doorstep frequency, minutes as their frequency is expressed in the bus arriving every " $\mathrm{x}$ " minutes and AI means " $\mathrm{x}$ " buses per hour

\section{PTAL calculations}

The PTAL are expressed as band of AI values, which are obtained using six calculation steps that are adapted from (Transport for London, 2015), and briefly explained below.

Firstly, the Point of Interest (POI) and Service Access Points (SAP) are defined. The area is divided into $1 \mathrm{~km}^{2}$ grid and centroid of each grid is considered as the POIs, and the PT stops for the city bus routes are referred to as the SAPs. Based on the existing road network, walking distance from each POI to SAP is measured (on a satellite map), assuming a walking speed of $3.6 \mathrm{~km} / \mathrm{h}$ and Walk Time (WT) is calculated. Average Waiting Time (AWT) is calculated considering all the routes and frequency of the service during peak hours. AWT is defined as the period from when the passenger arrives at SAP to the arrival of the desired service. A reliability factor $(\mathrm{K})$ is added to the Scheduled Waiting Time (SWT) which is assessed to 


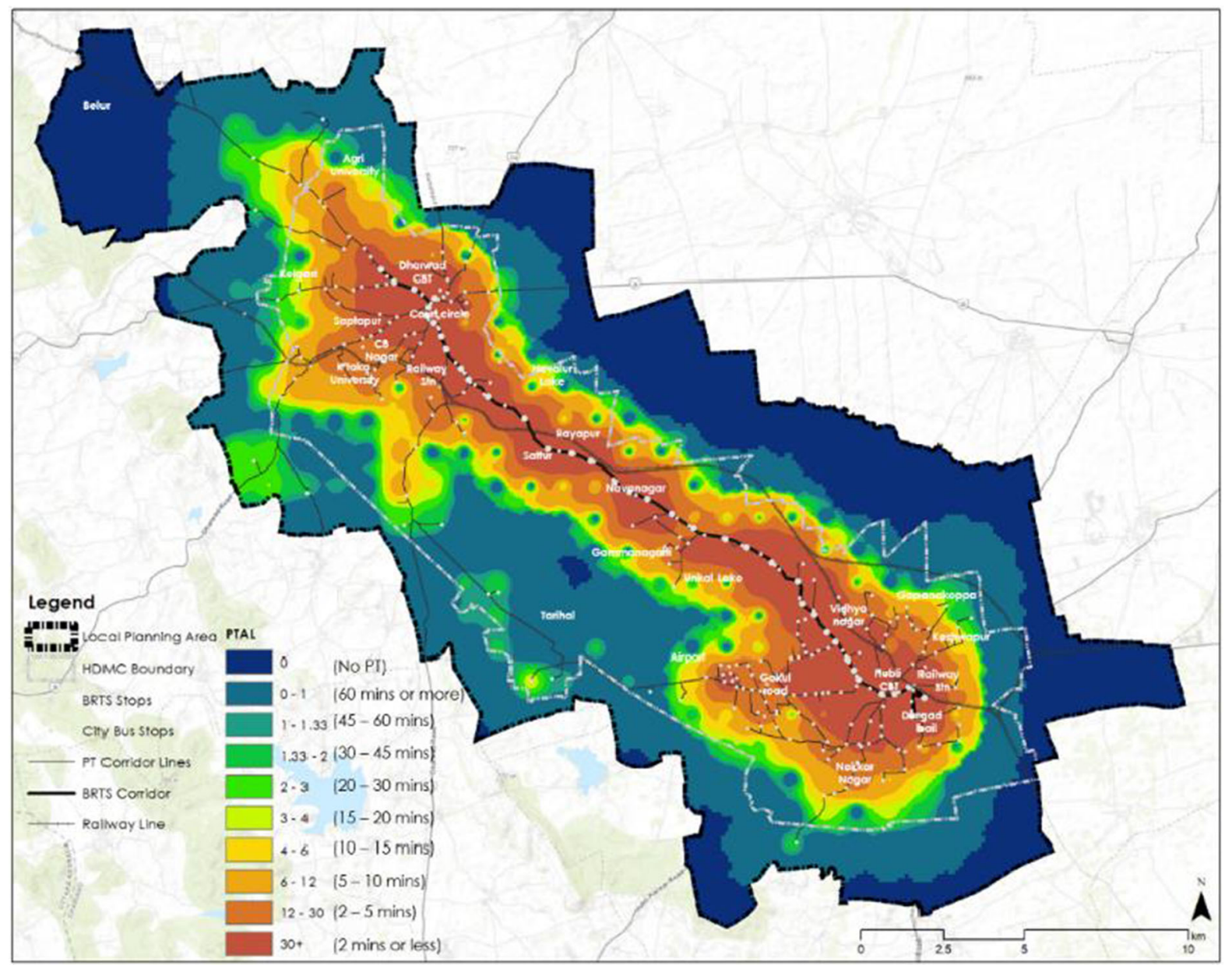

Fig. 5 PTAL 2020 (base year)

be half the headway. In public transport planning, headway is the time between consecutive services. For example, if the bus frequency is one bus service every $20 \mathrm{~min}$ and passengers arrive at the stop without considering the bus schedule then the average waiting time for the passenger would be taken as half the headway i.e., $10 \mathrm{~min}$. There are several hindrances for the transport services that cause en route delay as they ply in mixed-traffic (i.e. not on a segretated right-ofway). Therefore, a reliability factor is added depending on the PT mode, which for Hubli- Dharwad is taken as $2.5 \mathrm{~min}$ for city bus and $1 \mathrm{~min}$ for BRTS. The Total Access Time (TAT) is calculated, which is a sum of walk time, average waiting time (assumed to be half the headway), and reliability factor. Equivalent Door Step Frequency is obtained from the TAT values. The value is converted to a comparable number to the service frequency considering extra walk time taken to reach an SAP along with the reliability of service (Adhvaryu et al., 2019). Finally, Accessibility Index (AI) for each POI is calculated by allotting weightage 1 to the route with the highest frequency and 0.5 to all the other routes. The summation of total AIs for all modes of PT for respective POIs is the final AI. These AI values are then banded into different categories and allotted colour bands for visual representation. Detailed PTAL calculations are discussed in research papers by (Transport for London, 2010; Adhvaryu \& Shah, 2016; Adhvaryu et al., 2019; Adhvaryu \& Kumar, 2021) and therefore are not repeated here. 


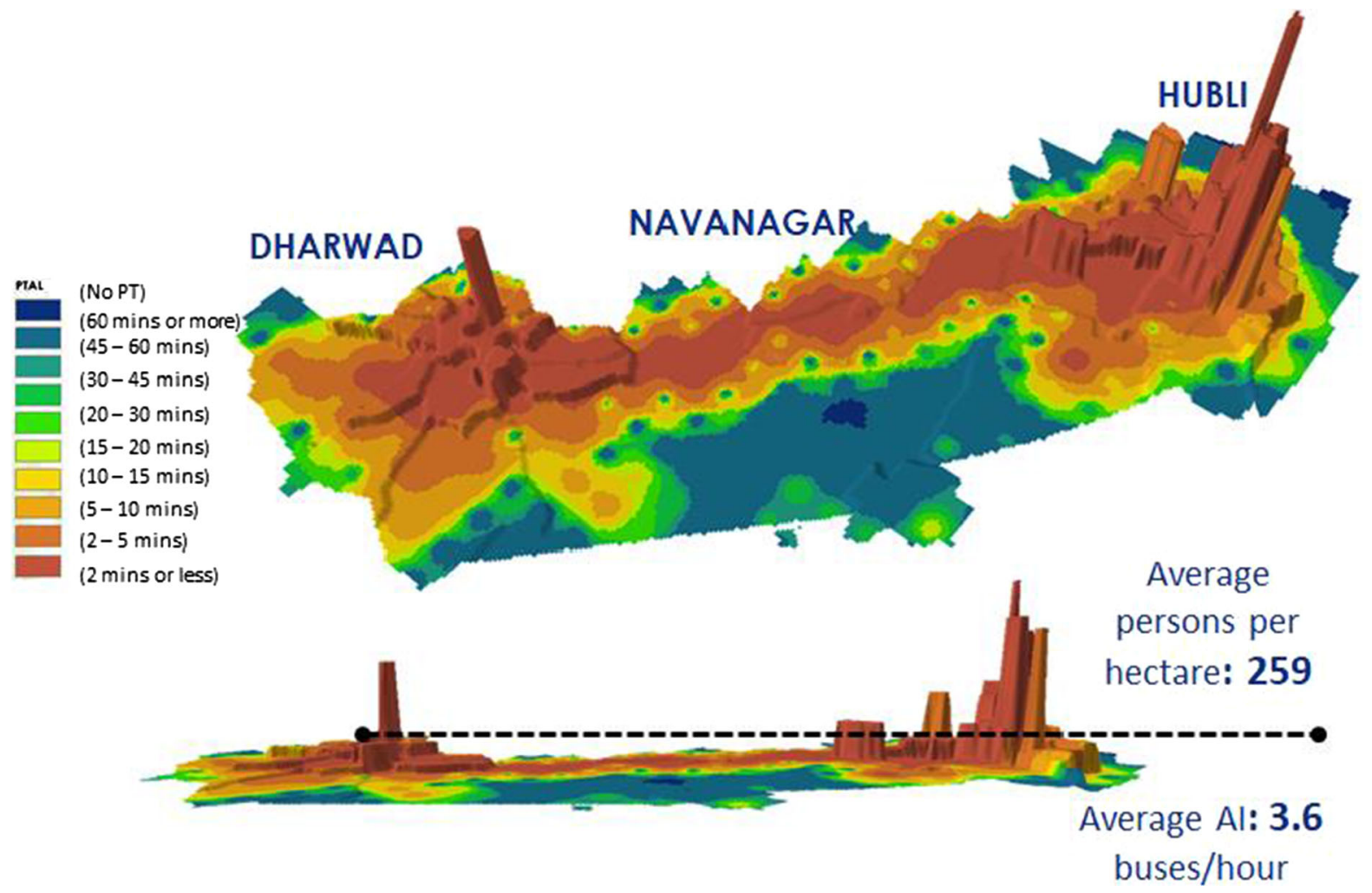

Fig. 6 3D visualisation of PTAL 2020 on population density based on 2011 census

\section{City profile: Hubli-Dharwad}

Overview

The twin cities separated by $20 \mathrm{~km}$ are one of the fastest-growing cities in the state of Karnataka, India (Fig. 1). They are the second-largest urban agglomeration after Bengaluru with a Local Planning Area (LPA) of 402sq km and an HDMC area of 202sq km (67 wards of 0.93 million population). The cities have interdependent economies, with Dharwad being the administrative headquarters and Hubli being a business hub. It has also lately emerged as an institutional hub of North Karnataka.

According to Census 2011, Karnataka with a population of 6.1 billion stands the third among the other States in using buses to commute to work. The State has a robust bus transport infrastructure for intercity and intracity travel. From Karnataka state's 31 districts, Dharwad district has the fifth-highest bus ridership for work (Census India 2011).
Since the cities are interdependent, which leads to frequent intercity commutes, people have always depended on the public transport. Therefore, the PT system has been most preferred in Hubli-Dharwad and has since evolved significantly.

In comparison with various Indian cities by population and the percentage of trips made by bus (Table 1), Hubli-Dharwad has 50\% of its trips by bus. This shows the magnitude of reliance on PT modes in Hubli-Dharwad. Therefore, in other cities where the main issue would be to increase the dependency on PT systems, Hubli-Dharwad has established a well-developed transit market in Karnataka. In 2018, BRTS upon its introduction increased its ridership from, passengers/day to 95,000 passengers/day within a year of its trial run.

Planning interventions

The planning for the local planning area (LPA) for the city of Hubli-Dharwad is as per the Karnataka Town and Country Planning Act, 1961. The Hubli-Dharwad 


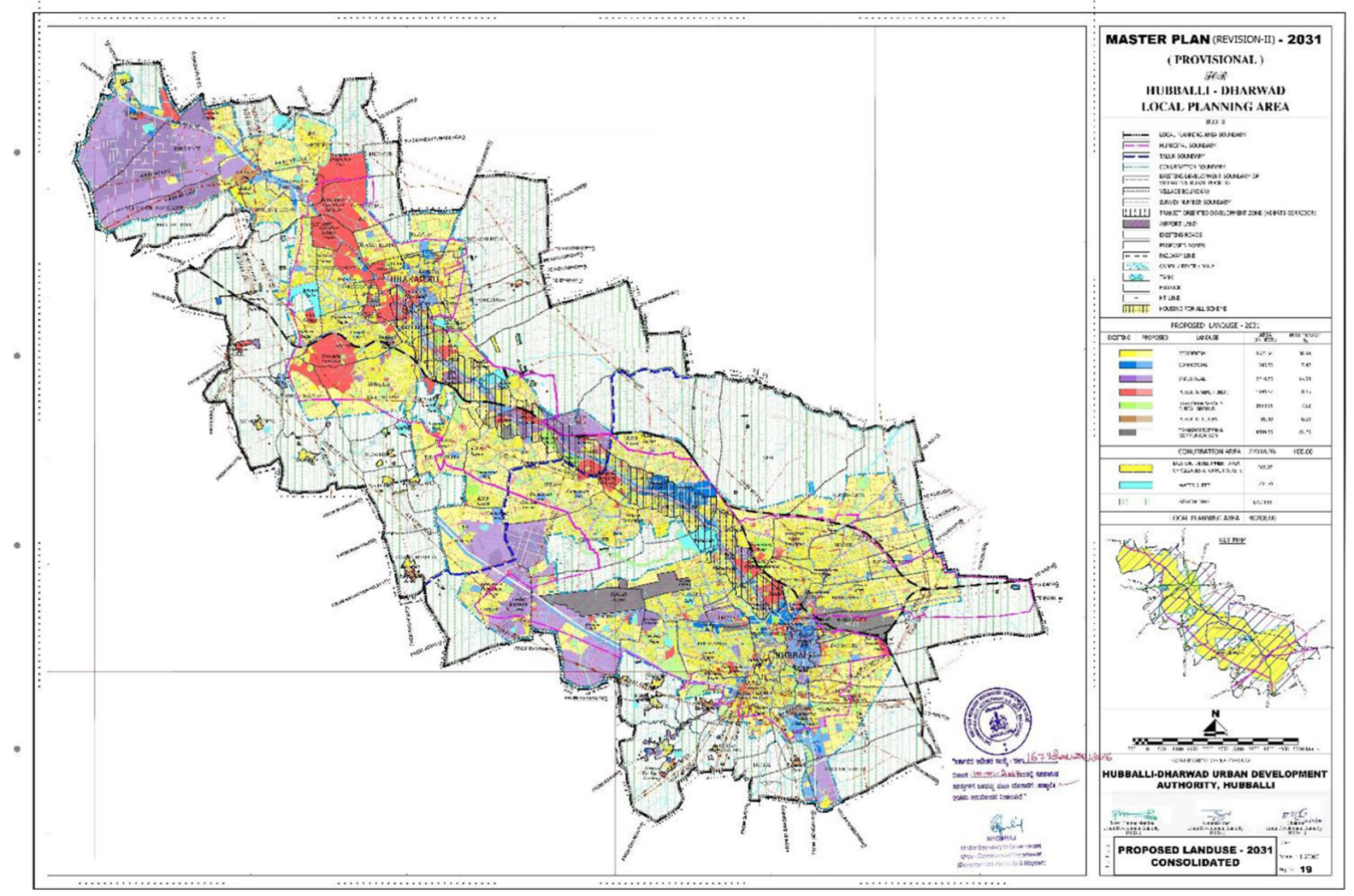

Fig. 7 Master Plan 2031

Urban Development Authority (HDUDA) is the planning authority entrusted with the work of formulation and preparation of the master plan for the LPA (HDUDA, 2018). The current master plan is for the horizon year of 2031 (made in 2017 and approved in 2019.) The vision of the plan is to make provisions for the future developments within the twin cities and make it the leading hub of economic activities of North Karnataka. The goal is to regulate a planned growth of land use within the twin cities and provide a suitable transportation network for future development. The current land use has been given a key priority in developing the proposed land use for the master plan. Since the Master Plan 2031 envisions Hubli-Dharwad to grow as a compact and equitable city, the public transportation infrastructure needs to be adjusted to follow the proposed developments where the activities are within short distances. Therefore, one of the key factors in creating future PTAL scenarios was to propose a public transport network that is in synchronisation with the development as proposed in the Master Plan.
The public transport system

The twin cities have grown linearly towards each other over the past five decades. The roads follow a radial pattern, originating from the city core towards the other city sub-centres. The shape of the city dictates the transportation network of the city. Due to longer trip lengths (7-8 km), dependency on PT systems has been prominent in the twin cities (IBI Consultancy India Pvt. Ltd, 2017). Buses comprise $7 \%$ of the total traffic and carry about $70 \%$ of the people (CEPT University, 2012). The current PT network operated by North-West Karnataka Road Transport Corporation (NWKRTC) has 224 routes (Fig. 2) with an average headway of $30 \mathrm{~min}$ and, a total ridership of 215,000 within the city and 400,000 including the suburban services per day.

With the increasing pressure on the only link connecting the two cities, BRTS was introduced in 2018. It aimed to connect the essential nodes between the cities and create a rapid transit corridor to improve the PT service and ridership within the town. The 


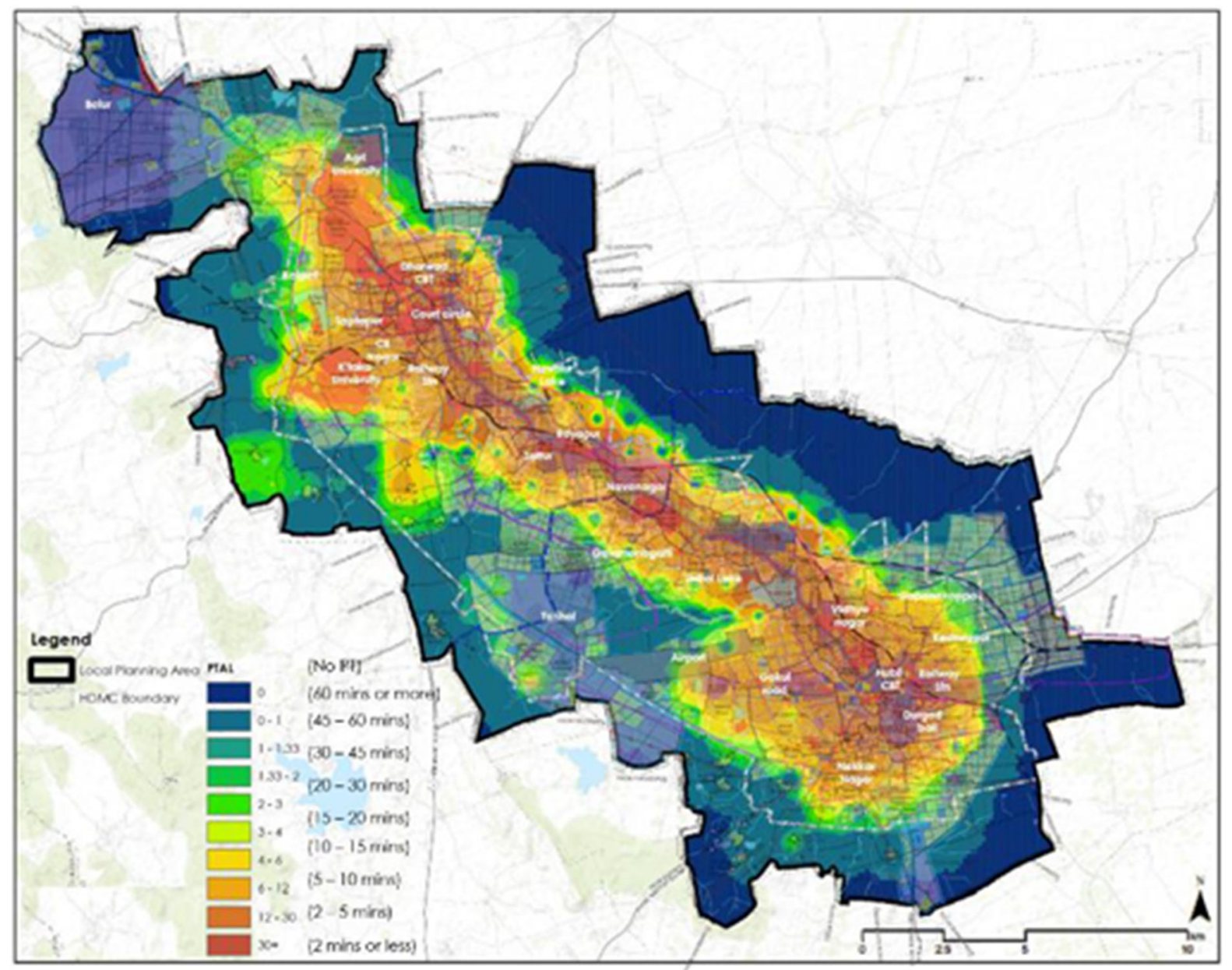

Fig. 8 PTAL 2020 overlaid on Master Plan 2031

corridor is $22.25 \mathrm{~km}$ (Fig. 3), which is the main trunk line with varying widths. It has 34 stops with a total of 4 routes with a frequency of $3 \mathrm{~min}$ from 8 am to $12 \mathrm{pm}$ and 4 to $8 \mathrm{pm}$. The service makes 1240trips/day. The average commute time is 55 min for "all stop" routes and $35 \mathrm{~min}$ for the "limited (express) stops" route (Hubballi-Dharwad BRTS Company Ltd., 2020).

Hinging on the accolades earned by the BRTS project and the complementary city bus network, mapping the PT accessibility in the LPA area is beneficial. The feeder network which connects to the trunk line does not entirely serve the local destinations within the city. Hence, gaps in this order shall reflect the service accessibility of the PT system, and this visual representation can facilitate planning in the improvement of the existing PT network and future demands.
Data collection and analysis

\section{Data collection}

The PTAL methodology tailored to Indian cities required few crucial datasets for analysis like bus routes, service frequency, bus stop locations, distance from point of origin to bus stops, and average walking speeds,. The city government agency NWKRTC, which is in charge of both city buses and BRTS in Hubli-Dharwad facilitated data collection for necessary computations. Data on walk time and preferred walking distance to PT stops were collected based on a sample of 25 volunteers of varying age groups, backgrounds, and income groups, like students, working professionals, and housewives. The volunteers were interviewed to understand their walking 


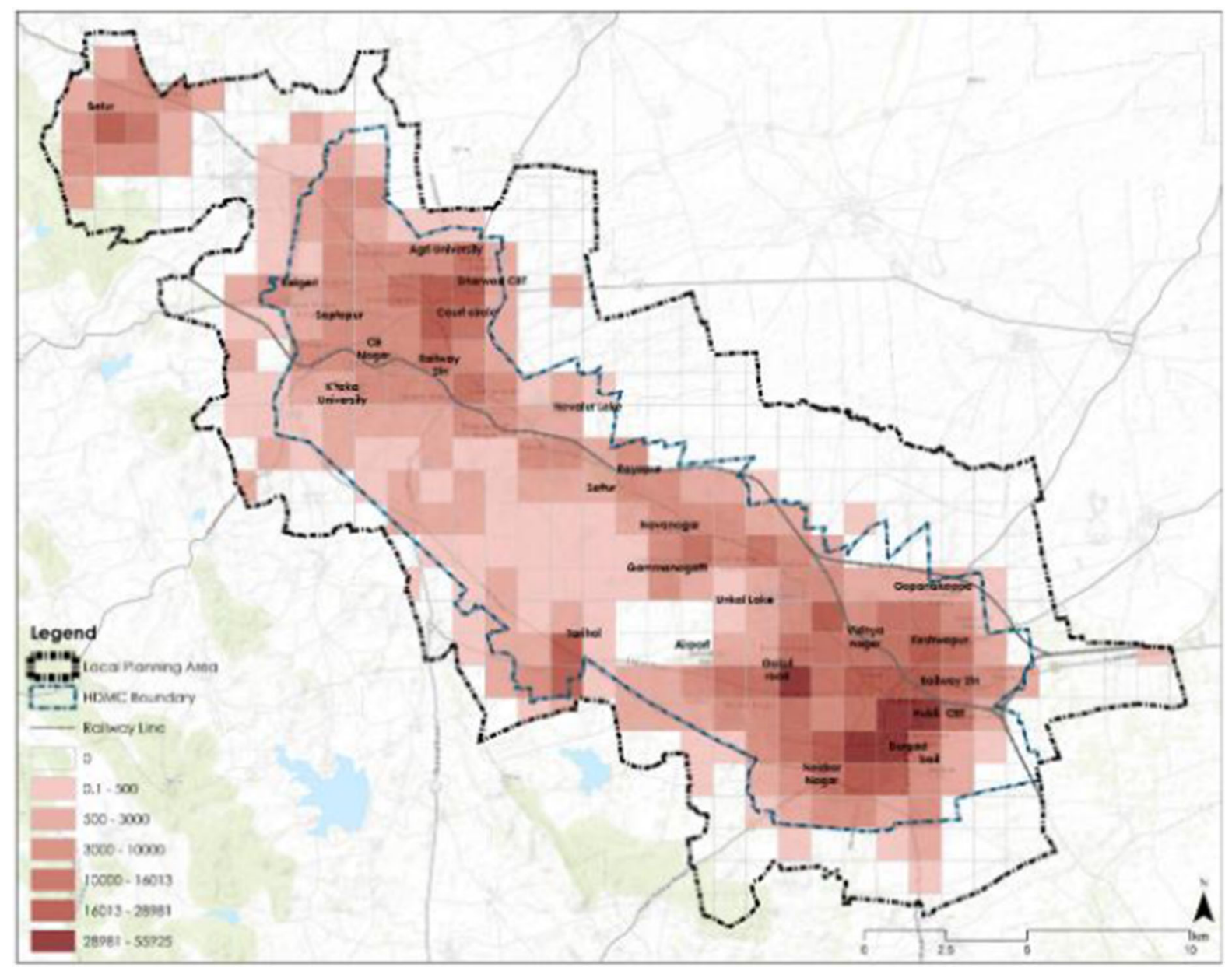

Fig. 9 Employment density (2020)

preferences for public transport stations for both city buses and BRT services. Also, the headway and delay were assessed on-site by observing the arrival of buses at various bus stop locations of city buses and BRTS across the city. About 10 buses were sampled at each location. The process of data collection began in December 2019 and ended by February 2020. Since the data was collected for the year 2020, the base year was selected to be the same. The impact of Covid-19 only worsened by the end of March in India and since the datasets were collected before the lockdown the pandemic had no significant impact on the dataset.
The base year (2020) PTAL mapping

\section{Adaptation to Hubli-Dharwad}

In Hubli-Dharwad PTAL mapping, $1 \mathrm{~km}^{2}$ grid approach is adopted for mapping. The Surat PTAL study shows the variation between the grids of $1 \mathrm{~km}$, $500 \mathrm{~m}, 100 \mathrm{~m}$, and $30 \mathrm{~m}$ from which it can be inferedr that although smaller grid sizes enhance the visual grain, it increases the number of POIs (by four times). This increases the computational time and the costs are not justified for a city-level study (Adhvaryu et al., 2019). Also, since the main aim of PTAL mapping is to support city-level strategic planning interventions for public transport, a larger grid size would suffice. Table 2 shows the comparative parameters 


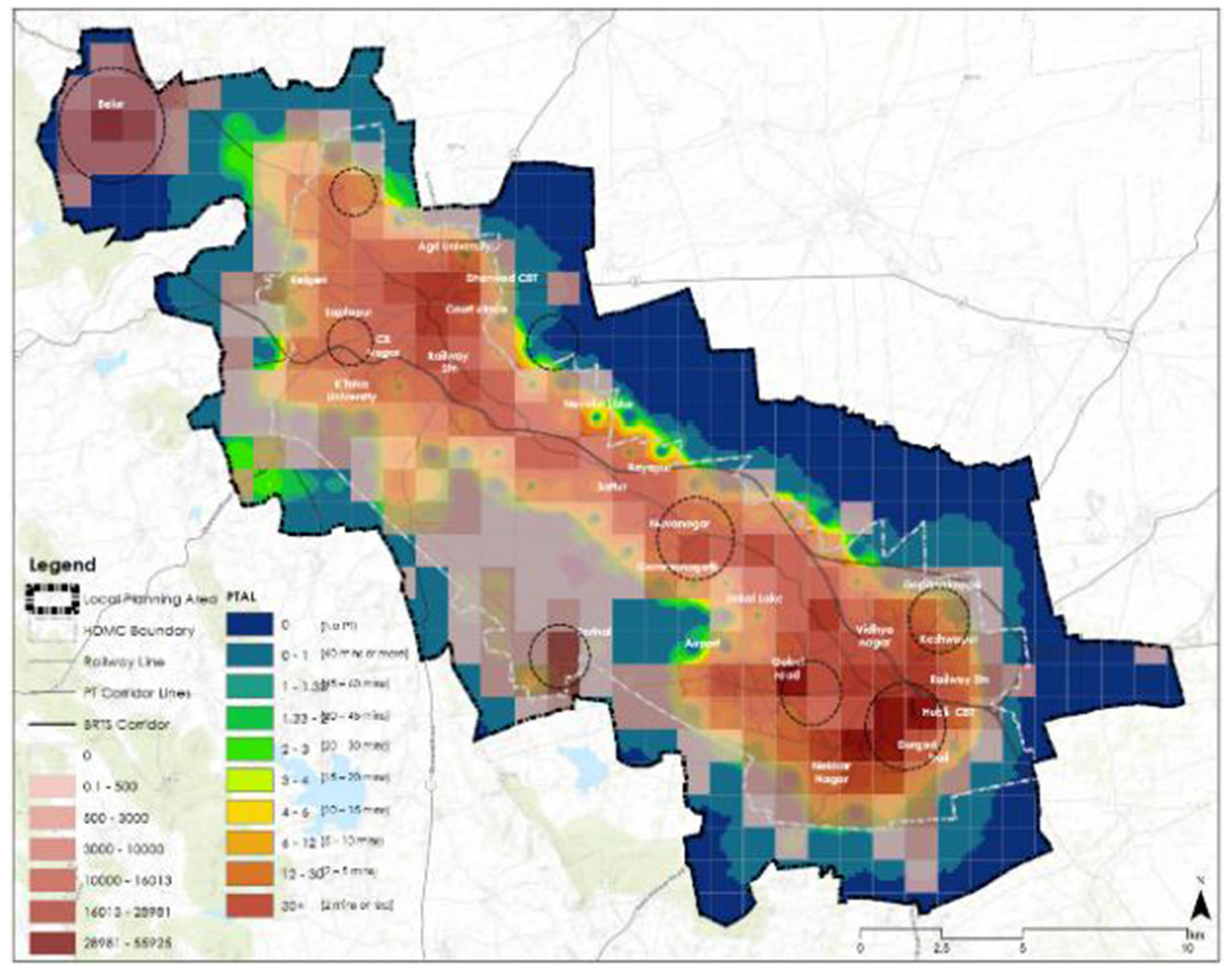

Fig. 10 Employment density overlaid on PTAL 2020

from the different studies and the sample AI calculation is shown in Table 3.

Analysis of PTAL

The total AIs calculated for all POIs are graphically represented on a map. ArcGIS software is used to map the AI values by generating Inverse Distance Weighted (IDW) values for the AIs. IDW values are then distributed manually into identified bands and given a pre-set band of colours. The manual categorisation aims to create bands represented in minutes of access time for a better understanding and interpretation by policymakers (Fig. 4), which is an innovation of this study. An equivalent representation of the access time is the accessibility index (AI), which is expressed in buses per hour in equivalent doorstep frequency (e.g. an AI of 4 means 4 buses/hour). Such round figures of AI are more relatable than, for example Level 6 of PTAL (as used in London), which is difficult to grasp intuitively. The PTAL map of Hubli-Dharwad (Fig. 5) is graded into accessibility levels ranging from 1 to 10 , where 1 shows an area with no PT accessibility and level 10 shows areas with excellent service accessibility. The PTAL map generated is for the combined service of the city bus and BRTS network.

The map shows the linear structure of the city. The level of accessibility decreases from the core city towards the fringes and increases along the linear corridor. The extension areas around Hubli and Dharwad with newer mixed-use developments, industrial areas in Belur, Tarihal, and Karwar road, are at medium and low service levels due to reduced 


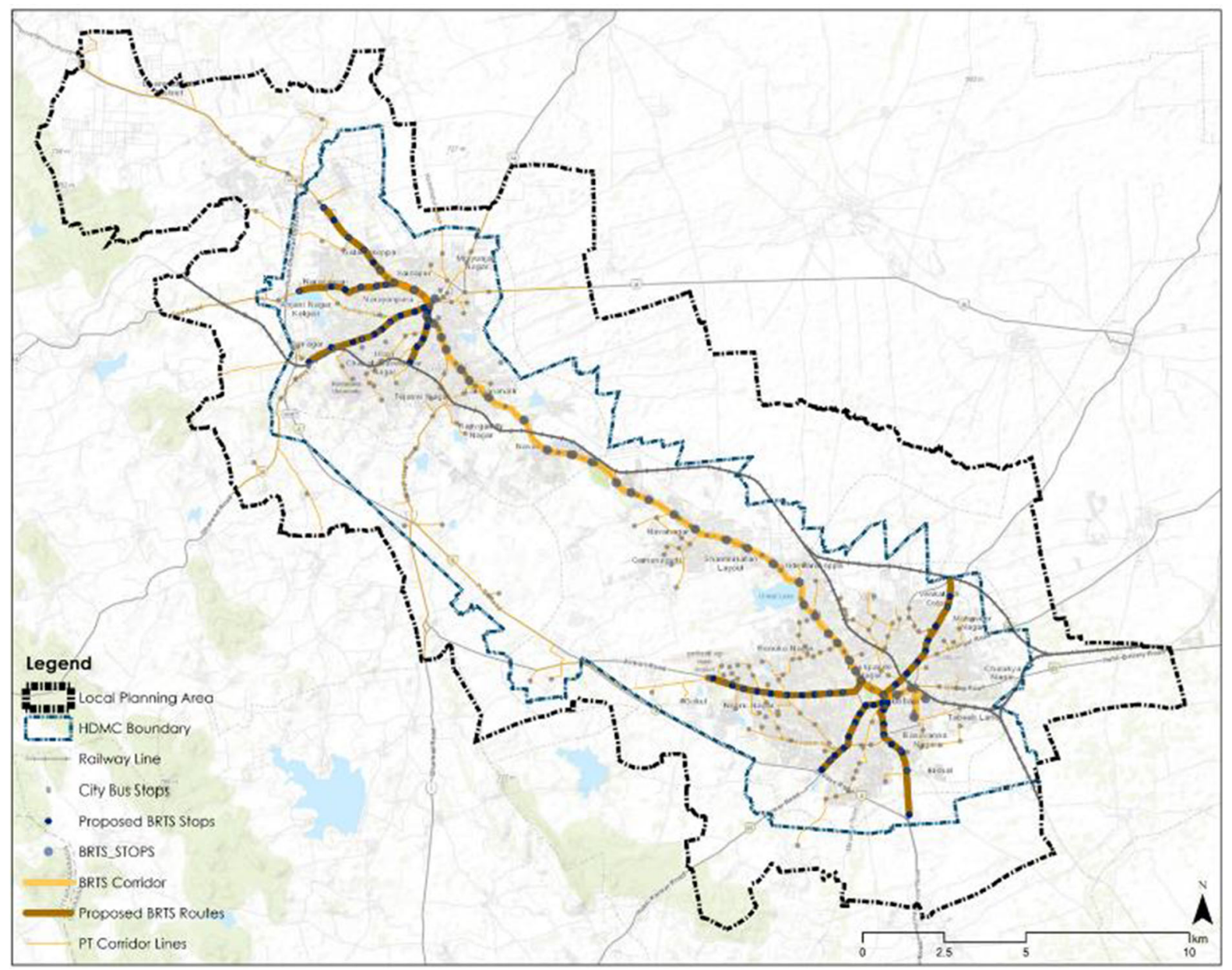

Fig. 11 Proposed BRTS feeder routes

frequency, lack of accessible bus stops, and routes. PTAL mapping, when overlapped with the population density of the city (Fig. 6), provides a visual representation of the service levels, wards with the highest population density have excellent PT accessibility levels. The PT network does justice to the city structure. However, analysis of various parameters with PTAL showcases the gaps in the service accessibility in the city. The areas developed in the last five years have medium to low accessibility levels but have high activity. Fifty-three percent of the slums remain at lower service levels which shows that the PT network is not equitable. The gap in service accessibility in the internal areas is filled up by intermediate public transport (auto-rickshaws). But these areas have a high potential to improve PT ridership. The average AI obtained 3.6 (buses/hour) and an average waiting time greater than 15 min. For a linear city, whose travel time between the city centres is roughly 50-60 min, the average AI value can be increased to improve the PT supply and its credibility. The AI values can be increased by improving the existing infrastructure or by introducing new additions to enhance the said infrastructure. This can be done by introducing new routes, increasing the number of bus stops, improving the station spacing, improving bus frequency, adding new modes of PT feeder services or non-motorised transport (NMT), and upgrading the street infrastructure to increase the walking speeds and comfort. These infrastructural interventions are at the discretion of the PT operating agency and city development authority, and hence can be incorporated based on city conditions like population growth, land 


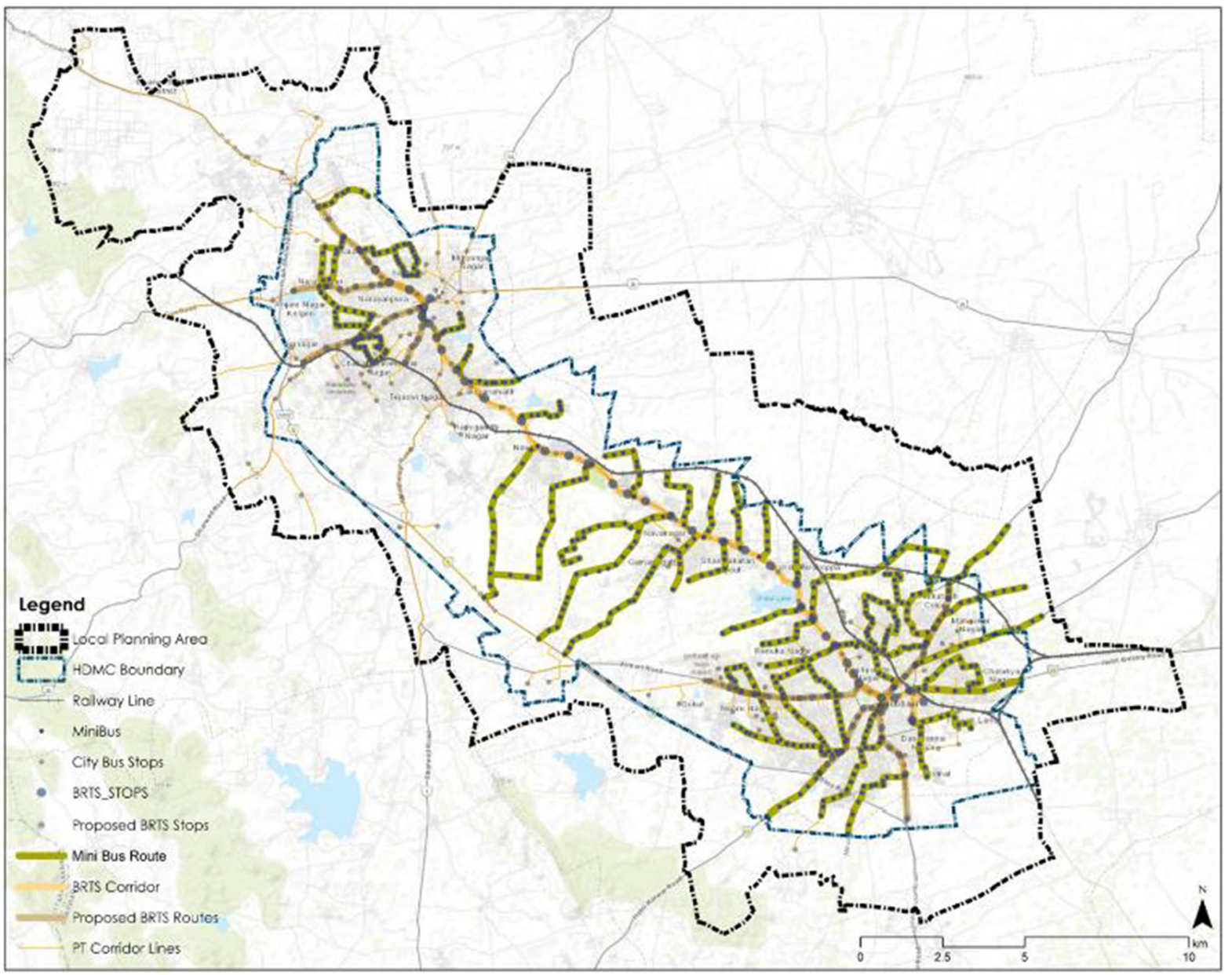

Fig. 12 Proposed mini-bus routes

use developments, and settlement patterns in the city, and as per the need for expansion of the network.

Land Use Transport Interaction (LUTI) models can also be used to help improve PT supply in the city (e.g. see SIMPLAN model, (Adhvaryu, 2010)). Since to predict and manage travel demand, the transport component of LUTI models focuses on understanding travel behaviour. Therefore, the modelling includes factors like trip origin and destination, transport mode choice, vehicle ownership, and trip scheduling/ sequencing behaviour. These attributes of travel demand can therefore facilitate decision-making to improve or increase the PT network. The impact of these improvements and additions on the Master Plan can also be visualised through LUTI models.

However, overlapping the Master Plan 2031 (Fig. 7) on the existing PTAL shows that the current
PT network does not cater to the new areas opened for development (Fig. 8). Newer PT additions and improvements are necessary to increase the accessibility to the area limits of the Master Plan 2031. The existing PT network is a mere reflection of the current city structure and its growth pattern by which it is evident that the two cities are sprawling radially independently and not growing towards each other.

The system fails to create a close-knit loop catering to all areas of the cities and establish a well-circulated PT network. The PT network needs to reflect the envisioned growth of the city as per the Master Plan 2031, which focuses on compact city development, establishing a more reliable connection between the twin cities, and reduce the mismatch between committed infrastructure provision and actual development. 


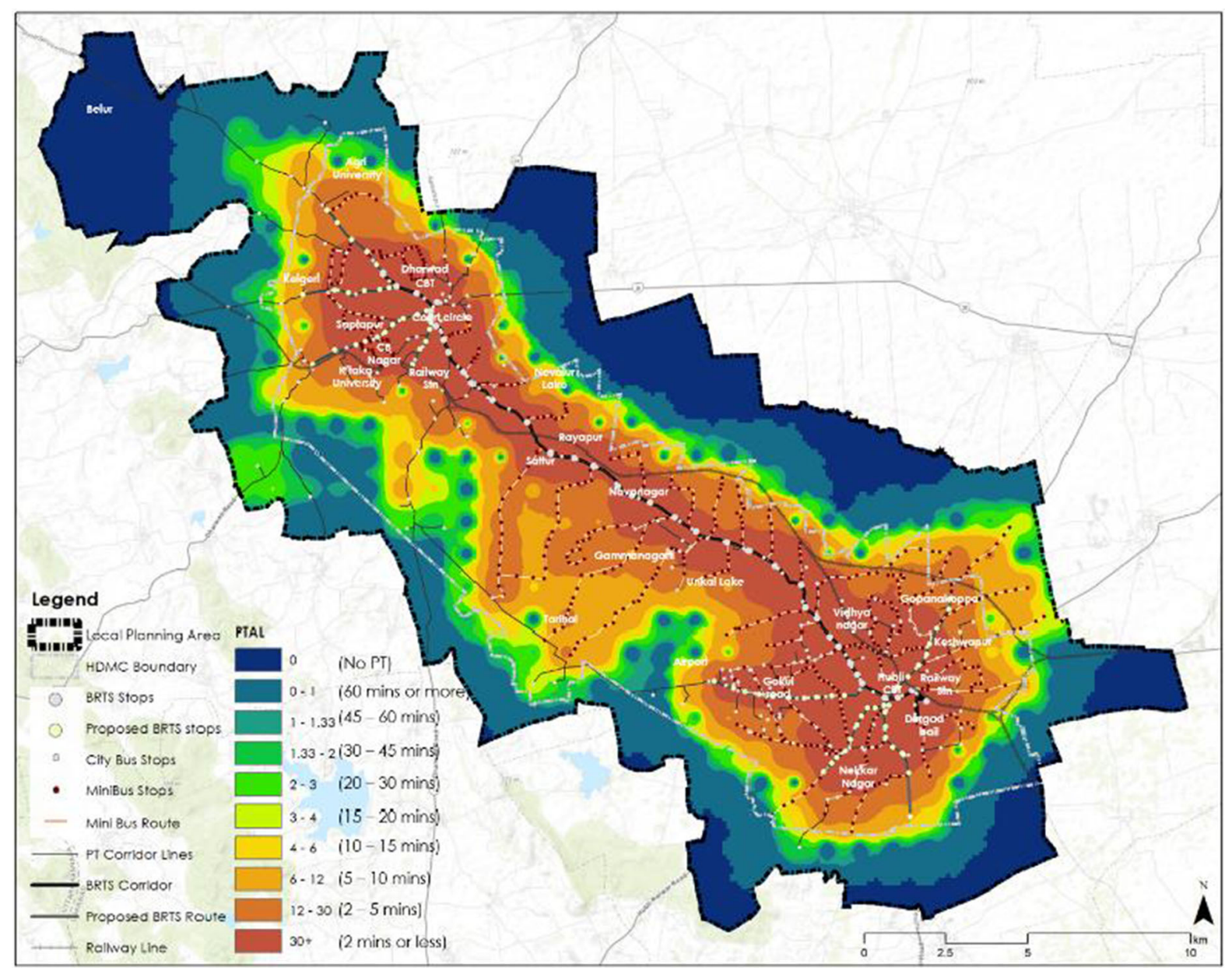

Fig. 13 PTAL 2031 with mini-bus routes

Varying levels of PT accessibility also influence employment characteristics and job dynamics within the city. Individual's choice of location of work travel to work. Access to transit significantly determines average labour participation rates to understand the spatial distribution of employment, a job density map was created for based on estimates of the average number of employees per square meter for different land uses like commercial, industrial, and administrative. It depicts the linear structure along the transit corridor supported by the two city centres (Fig. 9). PTAL overlay shows areas with higher employment density away from the core at lower service levels (Fig. 10). The current PTAL levels cater to most of the job centres located in the core city, but the peripheral and upcoming job centres experience lower service levels. With new areas being opened for development under Master Pan 2031, public transport services need to be designed to essentially link the residential areas with employment centres to yield employment benefits.

Future scenario: PTAL 2031 mapping

The future PTAL scenarios generated considering: (1) current accessibility levels to reduce the service gaps in the internal areas (2) the Master Plan of 2031 as a base and formulating a scenario to accommodate the future areas of development into the PT serviceability (3) improvement the network based on the growth pattern proposed in the (IBI Consultancy India Pvt. Ltd., 2018), assuming that the development follows the transportation links, and (4) stakeholder discussions and mapping future potential development zones 


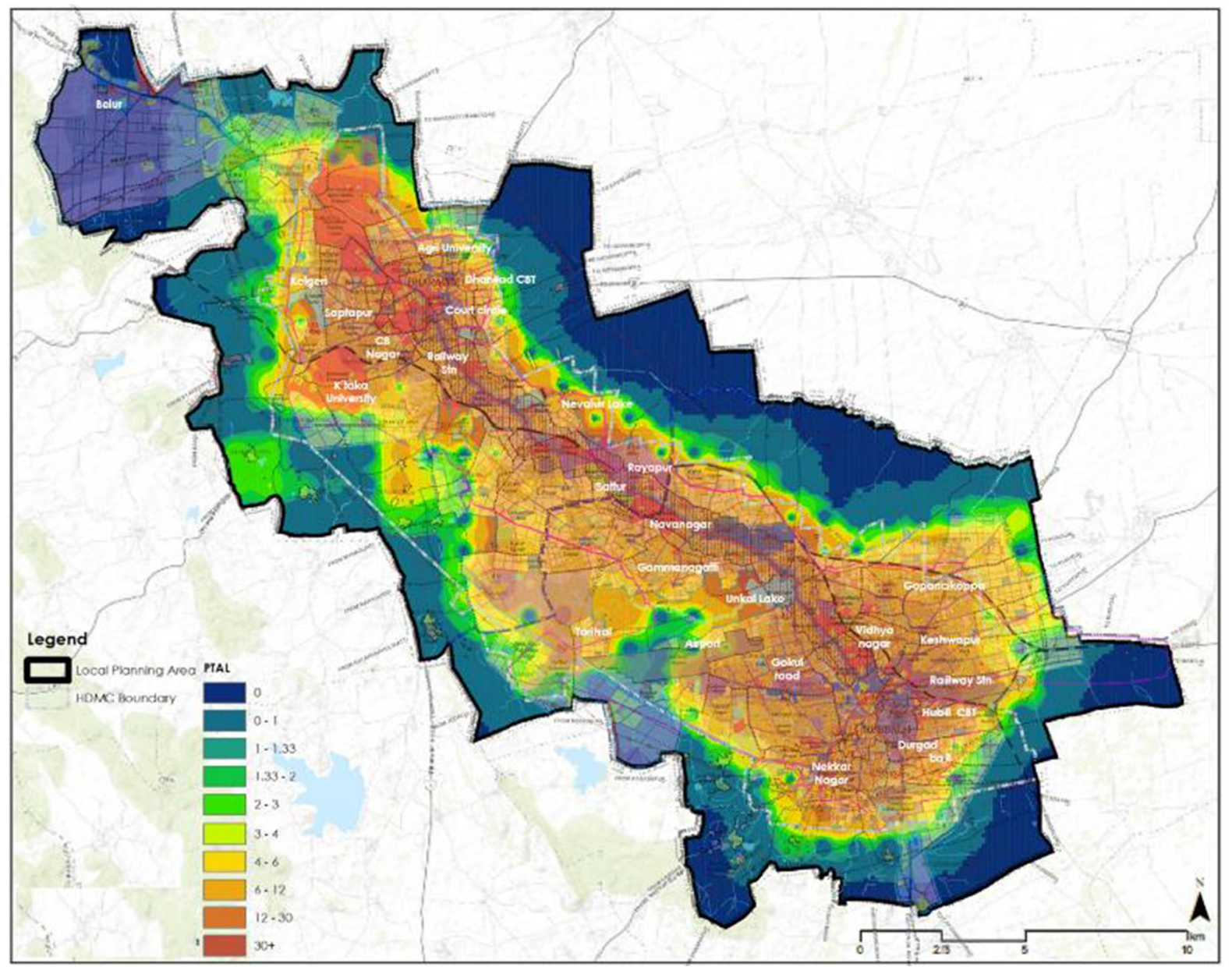

Fig. 14 PTAL 2031 overlaid on Master Plan 2031
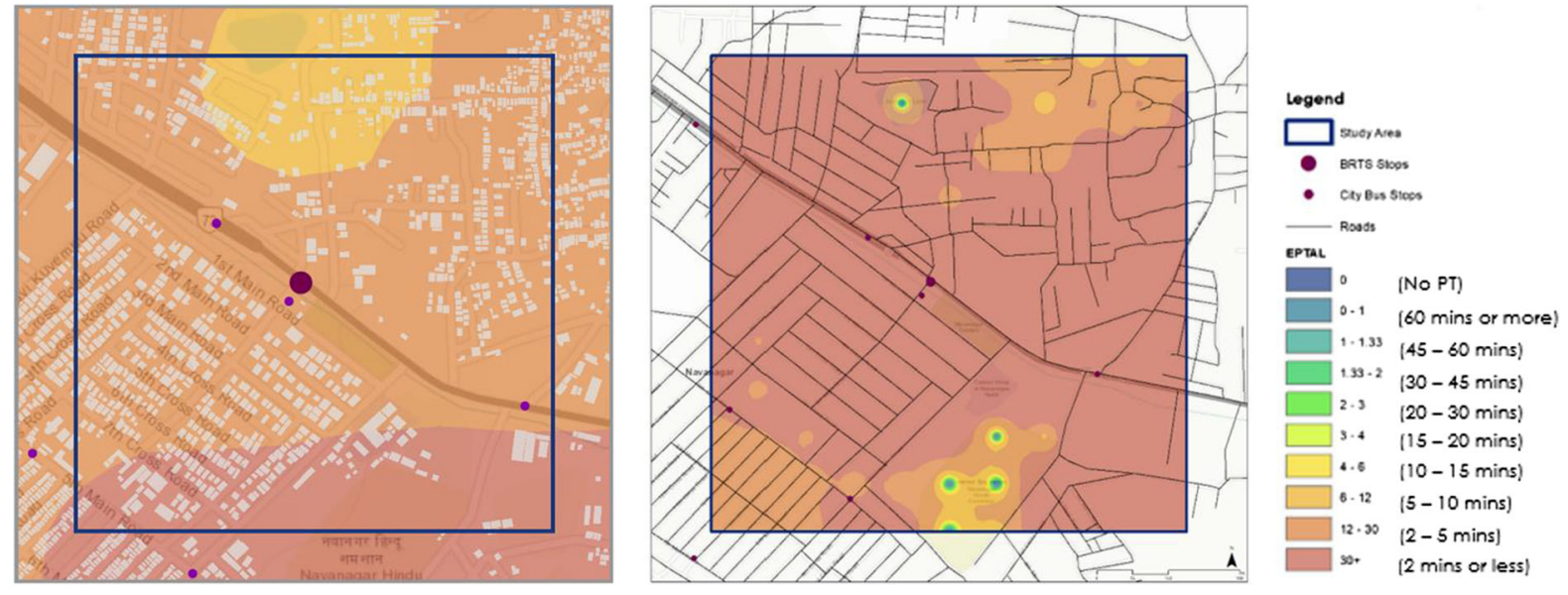

Fig. 15 PTAL comparison of Navanagar at 1 sq $\mathrm{km}$ grid (left) and 100sq m grid (right) 


\section{Existing growth pattern}

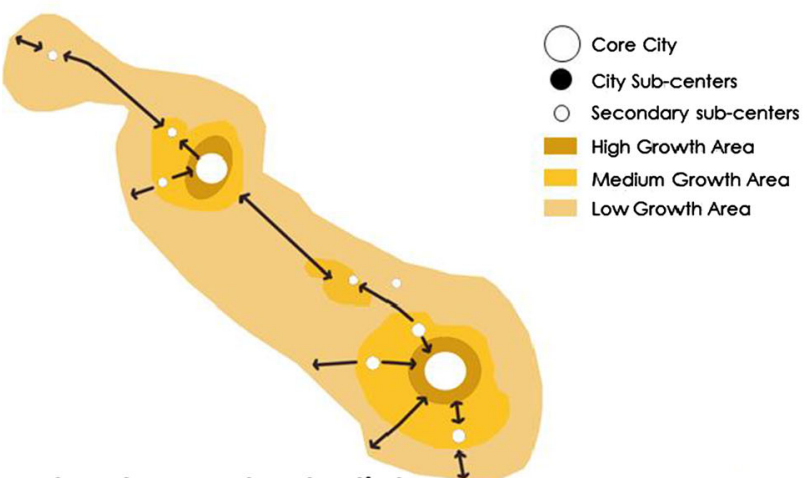

Future development potential

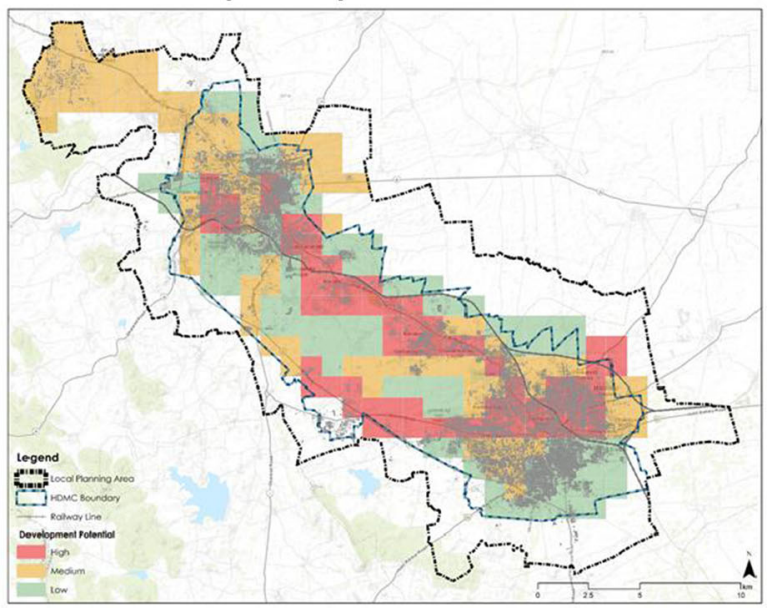

Fig. 16 Future growth and development potential with PTAL 2031

in the twin cities. Figure 17, which is introduced after the discussion on analysis of future PTAL shows the master plan intentions, future growth potential, and its overlay on future PTAL.

A "what if" scenario is generated to visualise the change in service levels by new PT investments. The network is proposed based on the growth potential, exiting route frequency, and gaps in service accessibility levels. Various parameters like existing land use, job distribution, income group distribution, slum locations, real estate scenario, multiple bus routes, and their frequency in the twin cities were studied. These parameters were further compared with the PTAL mapping to assess the accessibility scenario in the cities, analyse the shortcomings and propose interventions to improve public transport accessibility. The Master Plan 2031 was analysed with PTAL to

\section{Proposed growth pattern}

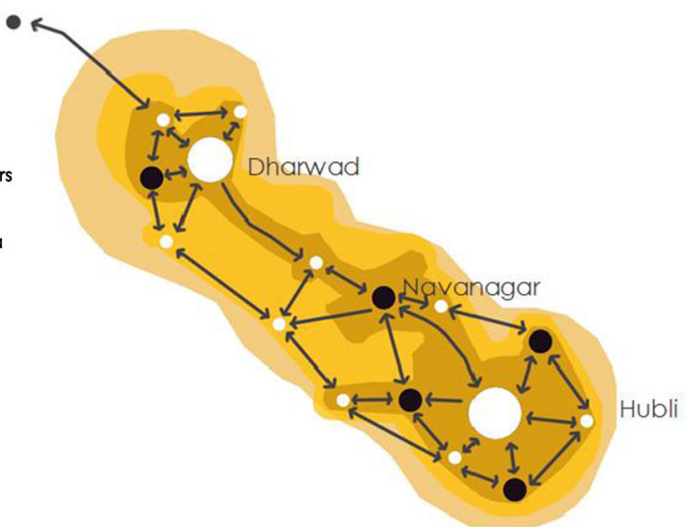

Future development potential overlaid on PTAL

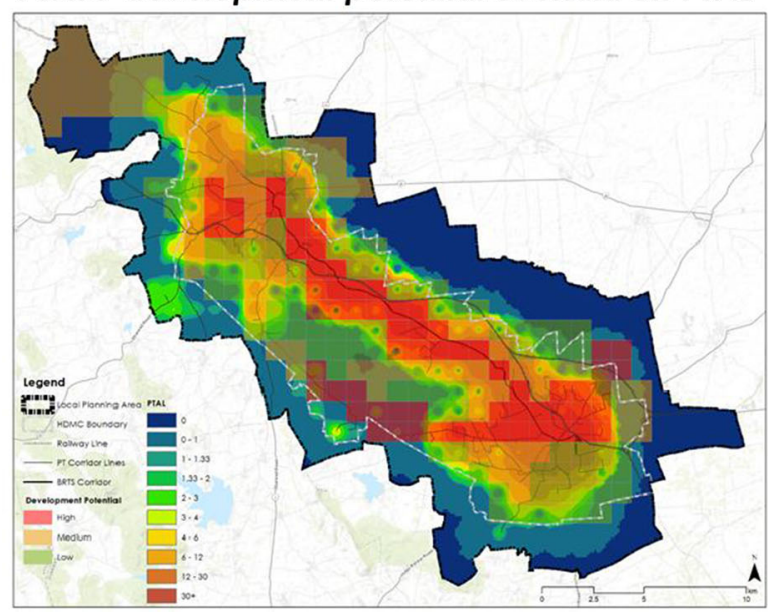

identify shadow regions of PT accessibility and further propose interventions to improve the network.

A BRTS feeder network based on the probable routes suggested in the Detailed Feasibility Report for HDBRTS (Fig. 11), and a mini-bus network (Fig. 12) running perpendicular to the BRTS lines are the proposed interventions. These proposals would increase access to the BRT corridor, improve its ridership, network credibility, and have a seamless first mile to last-mile connectivity.

\section{Analysis of future PTAL (2031)}

The introduction of the feeder network (Fig. 13) has visibly improved accessibility along major corridors; it connects more areas and facilitates dependency on rapid mass transport. Overlapping the future PTAL on the Master Plan 2031 (Fig. 14) shows that the PT 


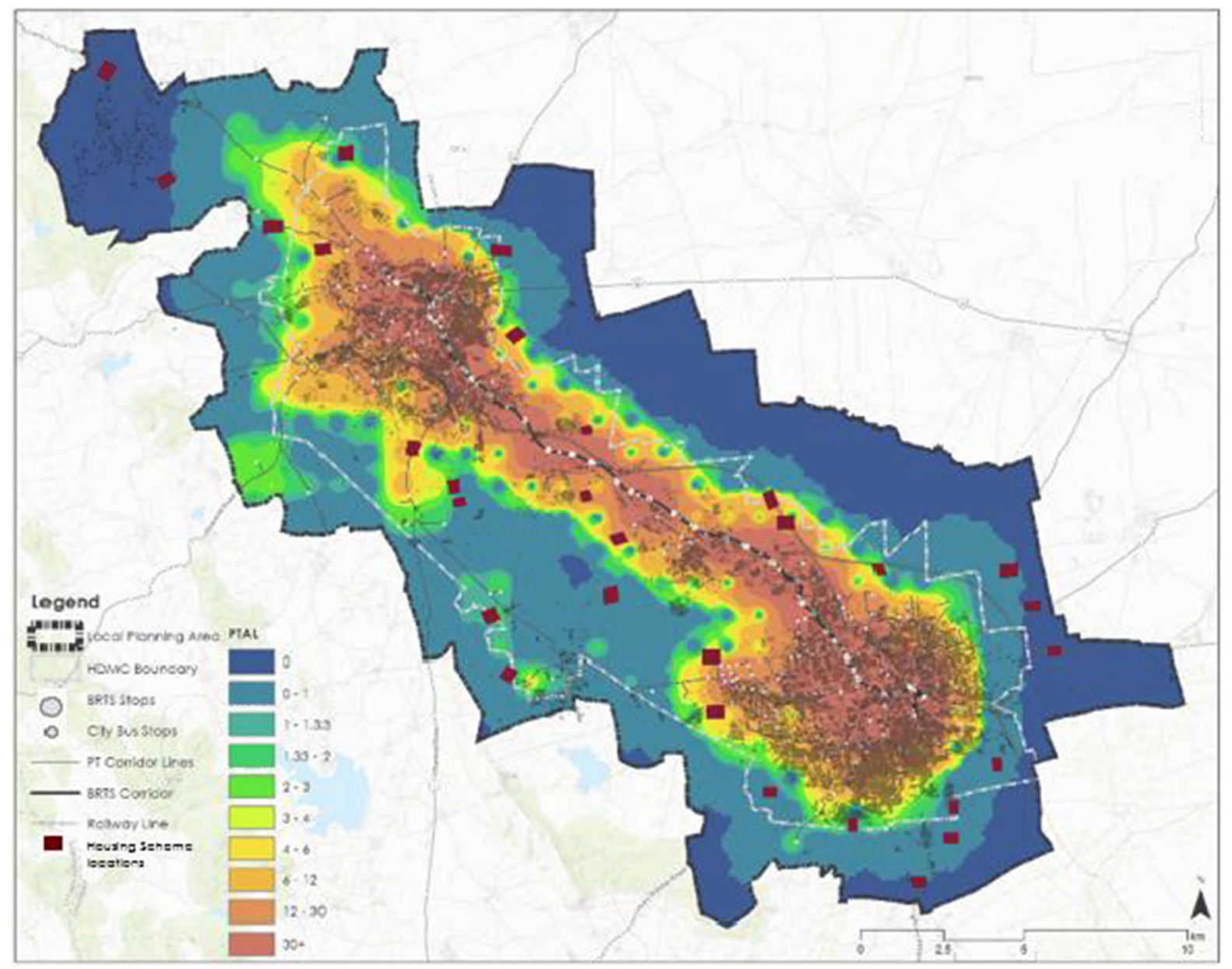

Fig. 17 Housing Scheme location on existing PTAL

interventions can cater to the proposed developments. The average accessibility index of the combined future PTAL increases to 5.5 (buses/hour) from the existing 3.6 (buses/hour), thereby reducing the waiting time. The future PTAL analysis based on various parameters showed how PT interventions could improve service accessibility. It reflects a service accessibility structure similar to the envisioned growth pattern of the city. Therefore, to propel the growth of the cities towards the vision, PT improvements need to be in tandem with future developments. This justifies that the PT infrastructure improvements would make a better and sustainable public transport system.

\section{Recommendations: PTAL applications}

- Prioritising investments in public transport: Areas of poor accessibility identified by PTAL mapping when overlapped with the population density can provide a visual representation of the areas requiring intervention. It facilitates strategic city-level planning, streamlines public transport and nonmotorised transport investment areas, route rationalisation, stops spacing, and frequency. Proposal to introduce mini-bus routes running perpendicular to the BRTS routes in Hubli-Dharwad to enhance the accessibility of public transport can be one such intervention to prioritise future investments in public transport. PTAL mapping can be done for micro-level planning like Local Area Plans (LAP) and Town Planning Schemes 


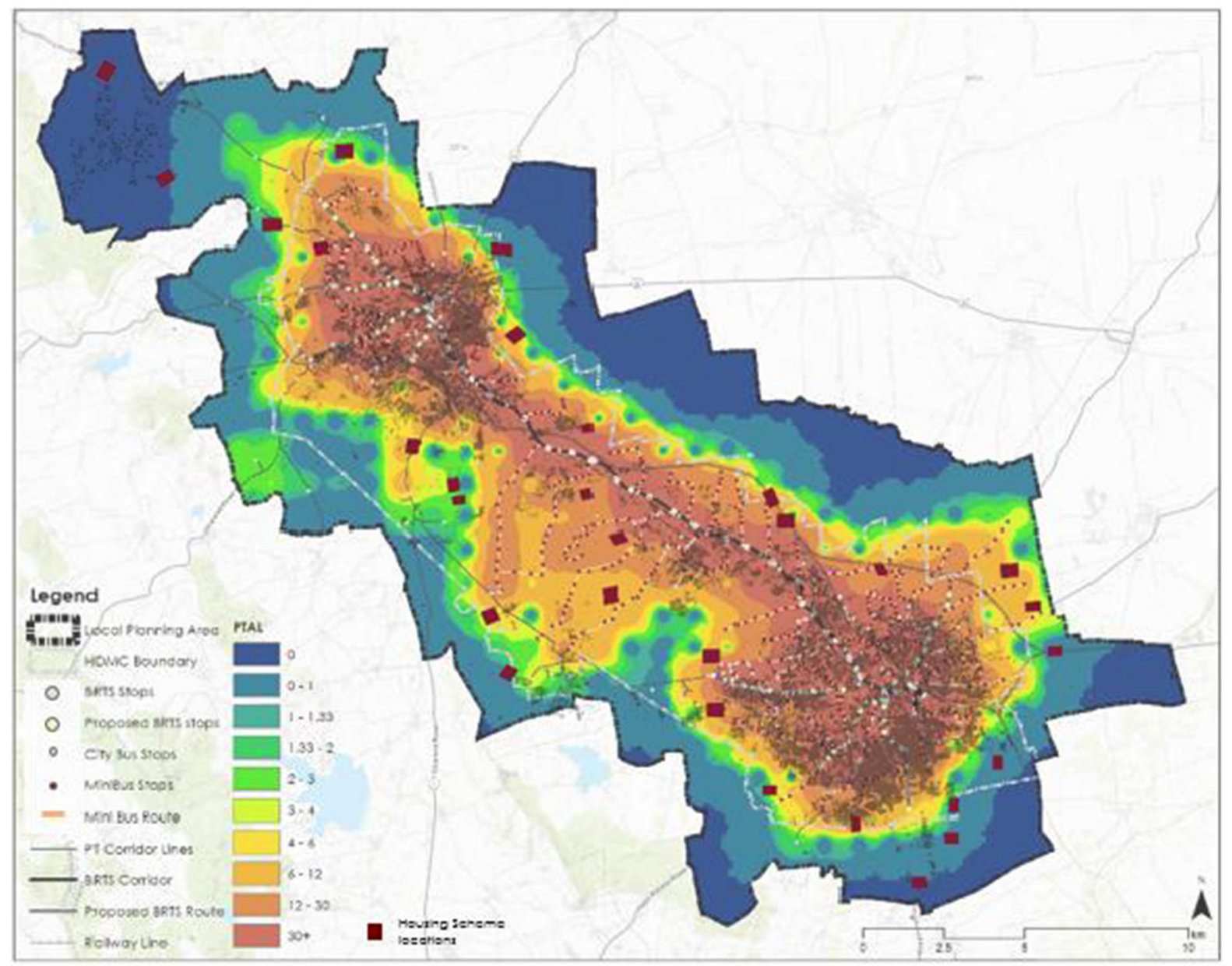

Fig. 18 Housing Scheme location on future PTAL

(TPS) for smaller areas with smaller grid sizes to obtain a finer grain of visuals to facilitate in planning the network of streets, NMT, basic infrastructure, density zoning, and land use. Figure 15 shows PTAL visualisation of the same one square kilometre area at both macro $\left(1 \mathrm{~km}^{2}\right)$ and micro $\left(100 \mathrm{~m}^{2}\right)$ scales for Navanagar, a township located between the twin cities. As can be seen, in the micro-PTAL map, some areas which were in high PTAL are now in lower PTAL. This implies that to improve the PTAL, more first-mile connectivity is required, e.g., by improving the pedestrian network. Of course, the PT service frequency and bus stop spacing can also be improved, all of which will increase the accessibility index. Local area infrastructure that contributes to improving PTAL is under of the relevant urban local bodies, who could explore public-private partnerships for its provision.

- Improving the Master Plan-making process: Planning a city for future expansion needs a base layer of the transport network. The growth of the city is linked to the road network and its supporting public transport system. Hence, it is crucial to assess the efficiency and accessibility of the public transport network, which can be done by PTAL mapping for current and future network scenarios, which feeds back in the plan-making process, achieving better integration of land-use and the transport network (Fig. 16). PTAL map generated for the twin cities can facilitate streamlining the areas to be opened for development in the future and plan for them to be in tandem with the transport network. 


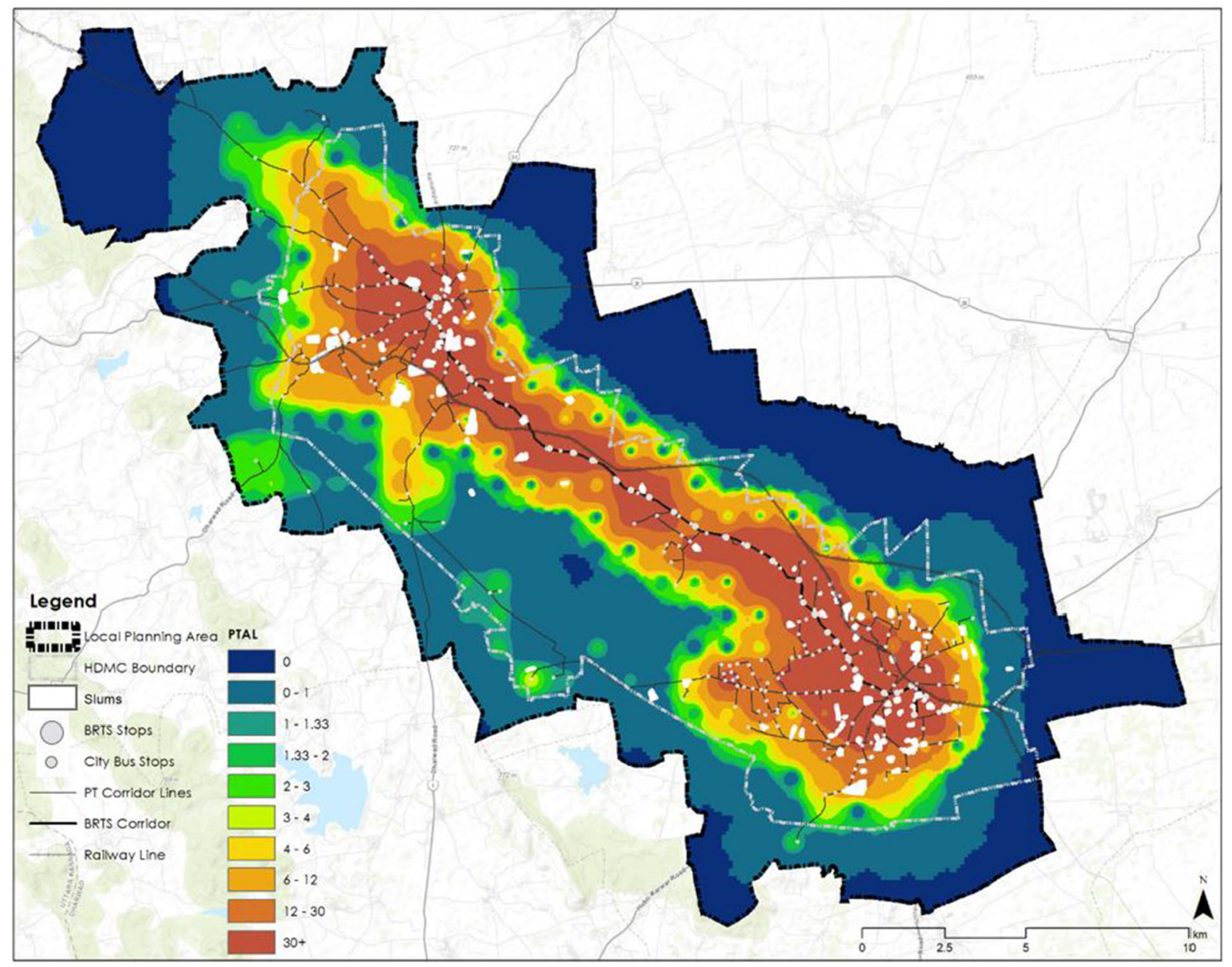

Fig. 19 Location of slum clusters on existing PTAL

- Formulating TOD policy and zone demarcation: Areas with excellent public transport service levels can be a pivotal contributor to TOD zones. The acceptable area that can be considered "transit-oriented" is dependent on how far people will walk to a transit stop or station. Research shows that transit riders will walk up to $400 \mathrm{~m}$ to a bus stop and $800 \mathrm{~m}$ to a train station, although in practice a portion of transit riders will walk somewhat more (Victoria Transport Policy Institute, 2019). Since walk distance which is one of the essential aspects of TOD zone demarcation, PTAL maps can be beneficial in demarcating TOD zone with more precision. The PTAL mapping of the twin cities can better inform the TOD zone demarcation, wherein areas with high PTAL values need to be taken into due consideration or as areas within the TOD zone need to be improved to achieve high PTAL values.

- Developing parking policy: PTAL can help regulate parking requirements based on the PT availability and access by treating parking as a commodity. Park \& ride facilities can be concentrated around weaker service level areas. On-street parking facilities can be detailed out using microlevel PTAL. Hubli-Dharwad can demarcate zones of no parking and park \& ride facilities based on the PTAL mapping to improve public transport patronage.

- Optimising affordable housing locations: PTAL mapping can help inform better residential location choices, prioritise the allocation of lands for "Housing for All" schemes, and promote infill and compact developments (Adhvaryu \& Rathod, 


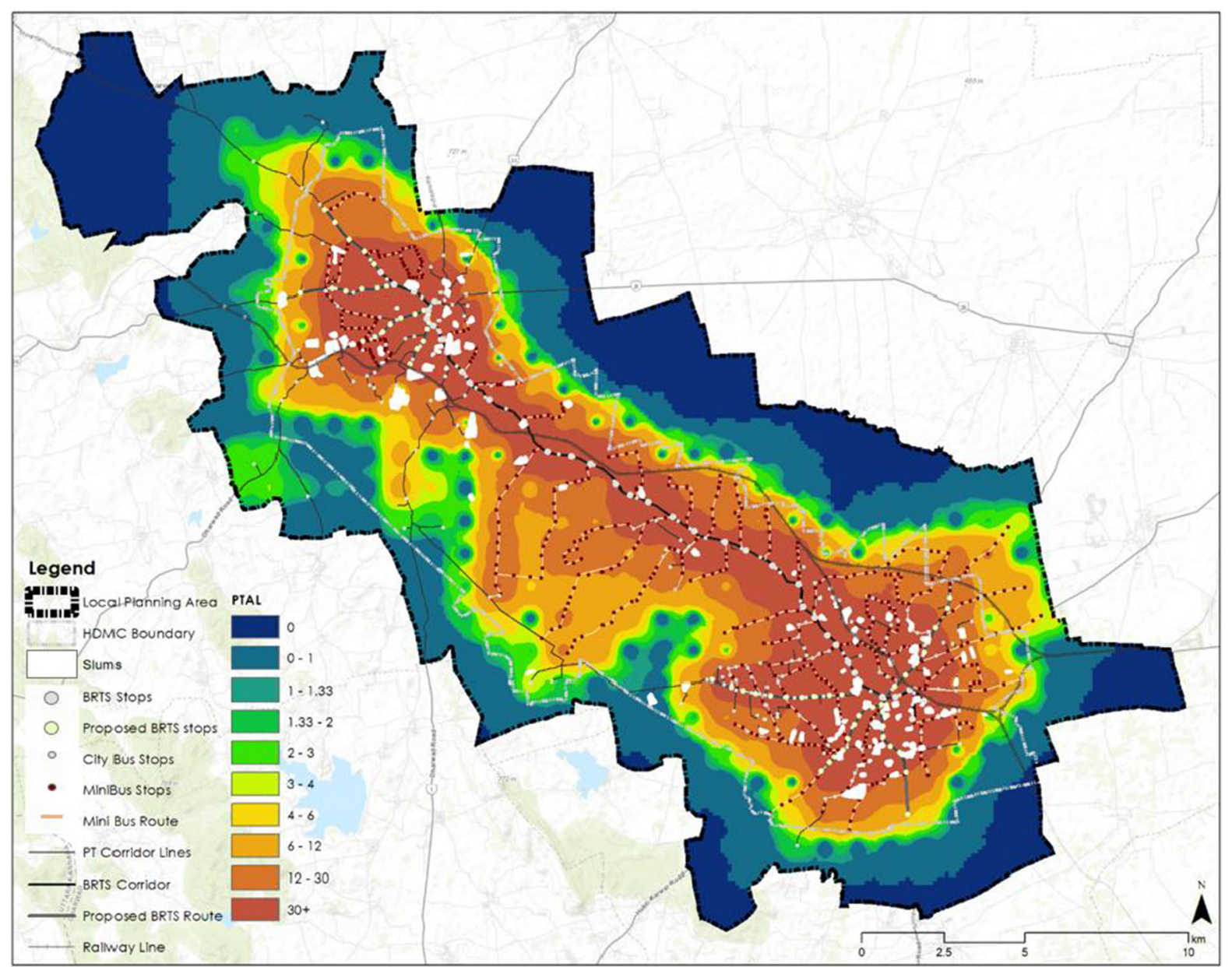

Fig. 20 Location of slum clusters on future PTAL

2019) since the population residing in these areas are more likely to be dependent on public transport. Affordable housing location in the twin cities has been spread across the urban growth boundaries based on the availability of government land parcels. Superimposition of the scheme locations on the existing and future PTAL maps can help assess the locational aspects of affordable housing zones (Figs. 17 and 18). It can help analyse the benefits of the locations in favour of the section of the targeted population.

- Improving the mobility of the urban poor: It is essential to understand the job density variations and the housing location of the urban poor within the city to improve the PT network to enhance their mobility needs. The superimposition of slum clusters on the PTAL map can help identify the areas with lower service levels, following which interventions can be planned to improve PT accessibility to these areas (a detailed application of PTAL for improving urban mobility is discussed in (Adhvaryu \& Patel, 2019)). The current system of the twin cities has $53 \%$ of the slum areas under lower service levels. PTAL mapping can provide a base to enable network improvement in the slum pockets in the fringe areas to provide better access to the PT network (Figs. 19 and 20).

\section{Conclusion}

This study discusses the mapping of public transport accessibility for Indian cities taking Hubli-Dharwad as a case study. PTAL mapping can be used as a visual 
tool to assess the existing public transport system of the city and also forecast the possible scenarios of public transport improvements and investment which are in synchronisation with trends and planned urban development. This can help in the strategic spatial planning of the city on both macro and micro scale. This study developed the PTAL mapping for the existing conditions and its influence on the population and job density and its implications for the city. It also demonstrates the future "what if" scenarios with a possible extension of the public transport network to service more significant areas of need and reduce the service gaps of the existing system, thereby evaluating the potential future PT investments. With the simplicity of the mapping tool, the scale of the mapping can be revised as per the need, and PTAL can be developed for micro-level planning like locality-based and areabased spatial scales. Thus, PTAL mapping can be a baseline to build upon the various layers of urban planning inputs for the city and better inform and guide the land use distribution, infrastructure and enhance transportation networks for the city. The mapping can greatly influence land use and transport policy. Given its simplicity of use and need for minimal data, it should be one of the essential decision-support tools for urban plan-making in India.

Acknowledgements The authors would like to thank the officials at HDBRTS Company, Hubli-Dharwad Urban Development Authority (HDUDA), Hubli-Dharwad Municipal Corporation (HDMC), and Visions Solutions for sharing the necessary data, information, and their insights. Both the authors were based at CEPT University during part of the study in early 2020.

\section{Declarations}

Conflict of interest We hereby disclose that there are no potential conflict of interests.

Human or animal rights Our research does not involve human participants and/or animals.

\section{References}

Adhvaryu, B. (2010). Enhancing urban planning using simplified models: SIMPLAN for Ahmedabad, India. Progress in Planning, 73, 113-207.

Adhvaryu, B., \& Kumar, S. (2021). Public transport accessibility mapping and its urban planning policy applications: A case study of Lucknow. Case Studies on Transport Policy. https://doi.org/10.1016/j.cstp.2021.08.001
Adhvaryu, B., \& Rathod, V. (2019). Estimating housing infill potential: developing a case for floorspace pooling in Ahmedabad India. Journal Planning Practice \& Research, 34(3), 305-317.

Adhvaryu , B., \& Patel , M. (2019). Is public transport in Ahmedabad inclusive? Ahmedabad: Economic \& Political Weekly.

Adhvaryu, B., \& Shah, J. (2016). Public transport accessibility levels for Ahmedabad, India. Journal of Public Transportation, 19(3).

Adhvaryu, B., Chopde, A., \& Doshora, L. (2019). Mapping public transport accessibility levels (PTAL) in India and its applications: A case study of Surat. Case Studies on Transport Policy., 7, 293.

Adwani, M., \& Tiwari, G. (2006). Review of capacity improvement strategies for Bus transit service. Indian Journal of Transport Management, 363-391.

Bertolini, L. (1999). Spatial development patterns and public transport: The application of an analytical model in theNetherlands. Planning Practice \& Research, 14(2), 199-210. https://doi.org/10.1080/02697459915724.

CEPT University. (2012). Bus rapid transit system hubli-dharwad- detailed feasibility report. Hubli-Dharwad: Directorate of Urban Land Transport (DULT).

Cheng, C.-L., \& Agarwal, A. W. (2010). TTSAT: A new approach to mapping transit accessibility. Journal of Public Transportation, 13(1), 55.

Wikimedia Commons. (2011, March 15). Wikimedia Commons. Retrieved from Wikimedia Commons: https://en. wikipedia.org/wiki/Dharwad_district\#/media/File: Dharwada-district-en.jpg

Wikimedia Commons. (2020, March 5). India Karnataka location map.svg. Retrieved from Wikimedia: https:// commons.wikimedia.org/w/index.php?title=File:India_ Karnataka_location_map.svg\&oldid=401701910

IBI Consultancy India Pvt. Ltd. (2017). City Plan for Hubli Dharwad. Hubli-Dharwad: Hubli-Dharwad BRTS Company Ltd.

IBI Consultancy India Pvt. Ltd. (2018). Hubballi-Dharwad 2030 City Development Framework . Hubballi-Dharwad: Hubli Dharwad BRTS Co.

Cooper, S., \& Inayathusein, A. (2018). London's Accessibility Indicators: Strengths, Weaknesses, Challenges. ITF.

EMBARQ. (2020, 4 23). Global BRT Data. Retrieved from Global BRT Data: http://brtdata.org/location/asia/india

HDUDA. (2018). Master Plan-2031(Revision-II) for HubballiDharwad Planning Area. Hubballi: Hubballi-Dharwad Urban Development Authority .

Hubballi-Dharwad BRTS Company Ltd. (2020, Feb). HubballiDharwad BRTS Company Ltd. Retrieved from HubballiDharwad BRTS Company Ltd.: www.hdbrts.com

Census India. (2011). Census of India 2011. New Delhi: Office of the registrar general \& census commissioner, government of india. retrieved from 'other workers' by distance from residence to place of work and mode of travel to place of work - 2011: http://censusindia.gov.in/2011census/Bseries/B_28.html

Victoria Transport Policy Institute. (2019). Transit oriented development - using public transit to create more accessible and livable neighborhoods. Online TDM Encyclopedia. 
Litman, T. (2012). Evaluating accessibility for transportation planning: measuring people's ability to reach desired goods and activities. Victoria Transport Policy Institute.

Mamun, S. A., Lownes, N. E., Osleeb, J. P., \& Bertolaccini, K. (2013). A method to define public transit opportunity space. Journal of Transport Geography, 28, 144-154.

Miller, E. J. (2018). Accessibility: Measurement and application in transportation planning. Transport Reviews, 38(5), 551-555.

Noland, R. B. (2001). Relationships between highway capacity and induced vehicle travel. Transportation Research Part A, 35(2001), 47-72.

Olaru, D., Moncrieff, S., McCarney, G., Sun, Y., Reed, T., Pattison, C., Biermann, S. (2019). Place vs. node transit: Planning policies revisited. Sustainability (Switzerland), 11(2).

Pitot, M., Yigitcanlar, T., Sipe, N., \& Evans, R. (2010). Land use \& public transport accessibility index (LUPTAI) tool - The development and pilot application of LUPTAI for the gold coast. Planning and Transport Research Centre (PATREC).

Pucher, J., \& Korattyswaroopam, N. (2004). The crisis of public transport in India: Overwhelming needs but limited resources. Journal of Public Transportation, 7(4), 95.

Saghapour, T., Moridpour, S., \& Thompson, R. G. (2016). Modeling access to public transport in urban areas. Journal of Advanced Transportation., 50, 1785-1801.

Transport for London (TfL). 2015 Assessing transport connectivity in London Transport for London

Wu, B. M., \& Hine, J. P. (2003). A PTAL approach to measuring changes in bus service accessibility. Transport Policy, 10, 307-320.

Publisher's Note Springer Nature remains neutral with regard to jurisdictional claims in published maps and institutional affiliations. 